\title{
Psychological Resilience to Major Socioeconomic Life Events
}

\author{
Fabrice Etilé*, Paul Frijters**, David W. Johnston*** and Michael A. Shields*** \\ * Paris School of Economics and INRAE \\ ** Social Policy, London School of Economics \\ *** Centre for Health Economics, Monash University
}

Version: $2^{\text {nd }}$ April 2020

\begin{abstract}
Understanding who in the population is psychologically resilient in the face of major life events, and who is not, is important for policies that target reductions in disadvantage. In this paper we construct a measure of adult resilience, document its distribution, and test its predictability by childhood socioeconomic circumstances. We use a dynamic finite mixture model applied to 17 years of panel data, and focus on the psychological reaction to ten major adverse life events. These include serious illness, major financial events, redundancy and crime victimisation. Our model accounts for nonrandom selection into events, anticipation of events, and differences between individuals in the immediate response and the speed of adaptation. We find considerable heterogeneity in the response to adverse events, and that resilience is strongly correlated with clinical measures of mental health. Resilience in adulthood is predictable by childhood socioeconomic circumstances; the strongest predictor is good childhood health.
\end{abstract}

Keywords: Psychological Resilience, Major Life Events, Non-Cognitive Skills, Childhood, Panel Data, Mixture Model

JEL: I10, C2, C5

Tables and Figures p. 36 and after.

We are grateful to the Australian Research Council for helping to fund this research, and to seminar participants at the London School of Economics and the Paris School of Economics for valuable comments. We are also grateful to Andrew Jones for comments. This paper uses unit record data from the Household, Income and Labour Dynamics in Australia (HILDA) Survey. The HILDA Project was initiated and is funded by the Australian Government Department of Social Services (DSS) and is managed by the Melbourne Institute of Applied Economic and Social Research (Melbourne Institute). The findings and views reported in this paper, however, are those of the authors and should not be attributed to either DSS or the Melbourne Institute. This is a revised version of an initial paper published as a Paris School of Economics Working Paper in September 2017 (WP 2017-09). 


\section{Introduction}

Talk about resilience is everywhere nowadays. Internet web searches for "Resilience and Government" provide countless examples of national and local governments highlighting the importance of resilience in individuals, communities, and businesses. Many governments now have dedicated departments, units, advisory groups, forums and online portals aimed at providing information and training to improve resilience. Examples include the UK Government's Community Resilience Framework ${ }^{1}$, and Public Health England's (2014) focus on building the resilience of children at school. ${ }^{2}$ Fletcher and Sarkar (2013) suggest that governments should provide communitybased opportunities that enable individuals to access environmental and personal resources that develop resilience. Policy-related initiatives include public education campaigns, mentorship programs for young people, and social groups for the elderly. The idea of building resilient communities is now a strategic goal of many national governments (see Longstaff et al., 2010; Cutter et al., 2013).

There are many definitions of psychological resilience, but a prominent one is provided by Bonanno (2004), who defines it as the ability of individuals "who are exposed to an isolated and potentially highly disruptive event.... to maintain relatively stable, healthy levels of psychological and physical functioning." For individuals, building psychological resilience is important because nearly everyone will experience a major adverse event at some point in their life, such as divorce, redundancy, serious injury, being a victim of crime, or the death of a partner or close friend. Individuals and communities may also be victims of natural disasters, civil conflict, or such criminal acts as mass shootings and terrorism. The questions then arise: how well do individuals cope with such events, and are some groups more resilient than others?

To answer these questions we use a novel, dynamic finite mixture model applied to a rich, nationally representative panel survey, to explore the extent of individual heterogeneity in the psychological response (our measure of resilience) to ten common major adverse life events. We also define a global measure of resilience as the expected inter-temporal loss of psychological health due to a 'standardised' event (SE), and derive from that a distribution for the population. Our model allows for heterogeneity in both anticipation and adaptation responses, while also attempting to account for the initial conditions problem and selection into events. We then document the relationship between resilience and adult socioeconomic characteristics, and explore the

\footnotetext{
${ }^{1}$ See: https://www.gov.uk/government/publications/community-resilience-framework-for-practitioners.

${ }^{2}$ Moreover, in recent decades, large-scale training programs for children, adults and teachers have emerged that aim to increase 'resilience', including the Penn Resilience Program (https://ppc.sas.upenn.edu/research/resilience-children), the UK Grit Program (www.grit.org.uk), and Australia's Resilient Youth (www.resilientyouth.org.au). Similarly, there are 'resilience courses' for emergency service workers (e.g. www.mind.org.uk), and the Rockefeller Foundation 100 Resilient Cities network (www.100resilientcities.org) is an example of a broad vision for resilient communities. Additionally, there are also hundreds of commercial training programs where 'leaders' can 'acquire personal and professional resilience'.
} 
distinctiveness of resilience from measures of cognitive and non-cognitive traits that have been the focus of a growing economics literature in recent years. Finally, we test whether adulthood resilience can be predicted by one's childhood socioeconomic environment. We believe that these analyses provide a salient integration of the limited literature on resilience in economics with the large psychology literature on this important topic.

Attempting to document the distribution of resilience in the population and in the context of different adverse events, and identifying the characteristics of individuals with different levels of resilience, is a valuable research task. As Clark (2016) notes, "The analysis of the distribution of resilience is of policy importance, as it would help to show us who needs more help, and in what circumstances." Cunha and Heckman (2009) stress the importance of research that can identify the mechanisms that promote resilience and recovery from disadvantage, noting a lack of systematic knowledge in this area. Similarly, Asheim et al. (2019) note that, "There does not seem to be much of a literature within economics when it comes to the measurement of individual resilience. This is somewhat surprising because there appears to be a clear link between resilience and individual and social well-being — and the high economic costs associated with mental illness."

However, while talking about resilience is easy, measuring resilience is a difficult empirical task. ${ }^{3}$ Bonanno et al. (2015) state that in order to provide a useful framework for understanding psychological resilience, a study must explicitly reference each of four temporal elements: baseline or pre-adversity functioning; the actual aversive circumstances; post-adversity resilient outcomes; and predictors of resilient outcomes. Moroever, A recent high profile review by leading resilienc researchers explicitly calls for more, "research on the dynamic processes of successful adaption to stressors in prospective longitudinal studies" (Kalisch et al., 2017). With these practical criteria, and this research call, in mind, we analyse nationally representative panel data from the Household, Income and Labour Dynamics in Australia (HILDA) survey, which tracks adult respondents from 2001 to 2017. This survey is well suited to the task because (1) it has followed a large sample over many years; (2) each wave it asks respondents about both their psychological health and the major life events they have experienced in the past 12 months; and (3) it asks respondents about their childhood socioeconomic circumstances.

In this study we estimate the distribution of psychological resilience in the population with respect to major adverse events, which substantively builds on much of the previous literature that

\footnotetext{
${ }^{3}$ In the psychology literature there remains considerable debate about how to define and measure resilience. One of the leaders in the field, Bonanno (2012) provides a discussion of what he calls the "uses and abuses" of the resilience construct. Fletcher and Sarkar (2013) note that, "One of the main difficulties in conducting research on resilience is that wide discrepancies exist in the way that resilience is defined and conceptualized." Also see the discussions in Luthar et al. (2000a,b). For an inter-disciplinary panel discussion of the definition of resilience see Southwick et al. (2014).
} 
often only focuses on one event. This enables us to derive an overall measure of resilience, as well as document the distribution of responses to each type of event. The ten events we focus on are: a major worsening in financial situation; being fired or made redundant; separating from spouse or long-term partner; death of a spouse or child; death of other close relative or family member; death of a close friend; serious injury or illness to self; serious injury or illness to a close relative; being a victim of physical violence; and being a victim of property crime. Notably, some $72 \%$ of respondents report experiencing at least one of these adverse events within our panel window.

Our empirical methodology expands on the latent class approach used by economists to explore heterogeneous responses in satisfaction (Clark et al., 2005; Brown et al., 2014) ${ }^{4}$, and on the latent growth mixture modelling approach used by psychology researchers to explore resilience (see Bonanno et al., 2010; Galatzer-Levy et al., 2010; Mancini et al., 20111 Galatzer-Levy and Bonanno, 2012; McGiffin et al., 2019). This methodological approach controls for many empirical issues, including fixed unobserved heterogeneity and anticipation effects; however, we cannot make any strong causal claims in this paper. Rather the motivation for the paper is a measurement model, designed to measure a fundamental individual trait (psychological resilience), which is not specific to just one life event, but more generally characterises individual reactions to any major adverse event. ${ }^{5}$ Rather than relying on any survey questions asked to individuals directly or indirectly about how resilient they are, we identify resilience through patterns of reactions to real life events. In doing this it is not practically possible to identify an instrument for each of the 10 major life events we study, and focusing on the causal effect of any one event using a single quasi-natural experiment for identification would not allow to characterise the distribution of resilience. Nor do we believe that psychological resilience can be measured well in experimental laboratory settings, as individuals need to experience a major event and we need to observe them in the years before and after the event. ${ }^{6}$

Using this modelling approach, we identify substantial heterogeneity in the psychological response to major adverse events. This heterogeneity is only weakly correlated with measures of cognitive ability and personality often used by economists in recent years, but is strongly correlated with clinically-related mental health measures. Finally, we find that childhood characteristics,

\footnotetext{
${ }^{4}$ Clark et al. (2005) use latent class techniques to allow for slope and intercept heterogeneity in the relationship between income and subjective wellbeing as applied to panel data from twelve European countries. They identify four classes of individuals, with individual characteristics and country of residence being significant predictors of class membership.

${ }^{5}$ Relatedly, Borghans et al. (2011) discuss the difficulty with identifying personality traits, where traits are often measured by observed behaviours including observer reports and test scores. However, they argue that behaviours are the result of incentives and traits, and that in order to isolate a trait then researchers need to control for the influence of all other traits and incentives. In this paper, compared to measures of resilience that would be based on purely hypothetical item questionnaires (such as the CD-RISC scale), we innovate by using ecological data where people are "naturally incentivised" by major life events, and we control for selection into such events.

${ }^{6}$ Thus we see this paper in the light of Ruhm's (2019) agrument of the importance of 'big picture' research for which it would be difficult to think of an experimental identification approach.
} 
including socioeconomic status, do significantly predict adulthood resilience. By far the most important factor linked with being a resilient adult is having good childhood health. That finding lends additional support to the importance of investing in child health, since a number of studies have also found that childhood health is strongly linked to economic outcomes in adulthood (for example, Case et al., 2005; Goodman et al., 2011).

The remainder of the paper is set out as follows. Section 2 discusses further background information and reviews the relevant literature, while Section 3 provides a detailed description of our empirical methodology, including our definition of resilience. Section 4 describes the data; Section 5 presents the main results on heterogeneity. In Section 6 we discuss how well adulthood resilience is predicted by childhood characteristics. Section 7 concludes.

\section{Background and literature}

Two broad aspects of resilience are explored in academic literatures. First, there are studies of the differential outcomes of children growing up with adversity and socioeconomic disadvantage. Second, there are studies of the factors that help to explain why adults, and to a lesser extent communities, differ in their psychological reactions to adversities and stresses (see, for example, Rutter, 1985, 1987; Cicchetti and Rogosch, 1997; Luthar et al., 2000b; Masten, 2001; Charney, 2004; Martinez-Torteya et al., 2009; Bonanno, 2012; Banny et al., 2013; Cicchetti, 2013; Amstadter et al., 2014; Howell and Miller-Graff, 2014; Bonanno et al., 2015). In addition, there have been four waves of resilience research, the most recent focusing on multi-level analysis and the dynamics of adaptation (Masten, 2007). Importantly, these related literatures have found that the factors explaining resilience are complex and multi-dimensional, spanning genetic, neurobiologic, temperamental, and environmental influences (Caspi et al., 2003; Charney, 2004; Boardman et al., 2008; Banny et al., 2013; Amstadter et al., 2014). It is most salient for policy interventions that resilience is seen to be modifiable to some extent on both individual and cultural levels (Connor and Zhang, 2006; Netuveli et al., 2008).

The good news is that most studies show that the majority of people do not experience severe psychological trauma or mental illness after experiencing a serious adverse event (see, for example, Rutter, 1985, 1987; Masten, 2001; Bonanno et al., 2010, 2015). Rutter (1985) summarised this, noting the "universal observation that even with the most severe stressors and the most glaring adversities, it is unusual for more than half of children to succumb. The same recognition has applied to adults to the development of depression following personal losses and rebuffs. Although risk of depression following disturbing adverse events is increased, it is usual for most people not to become depressed in spite of the stressful experiences". Similarly, Masten (2001) describes the ability of the majority of children to overcome significant adversity as arising from "ordinary magic", with individuals being 
capable of "astonishing resistance, coping, recovery, and success in the face of adversity, equipped with the usual human adaptational capabilities and resources, functioning normally" (Masten and Powell, 2003).

A subset of the resilience literature has focused on identifying distinct types or classes of individuals according to how they respond to adverse events. The most researched is bereavement. In terms of the psychological response to the death of a spouse, Bonanno (2004) identified five distinct response profiles; $35 \%$ of individuals experience significant trauma before and after the loss (classed as 'chronic depression'), while 46\% suffer no trauma (classified as 'resilient'). More recent research has found that $69 \%$ of individuals are resilient following the death of a spouse or child (Maccallum et al., 2015). Reviewing the literature on natural disasters, Bonanno et al. (2010) conclude that serious psychological harm rarely affects more than $30 \%$ in most samples, and "often more than half of those exposed, experience only transient distress and maintain a stable trajectory of healthy functioning or resilience." A third example is post-traumatic stress following a mass college campus shooting. Here, Orcutt et al. (2014) identify four response trajectories: $61 \%$ of students are classified as 'minimal impact-resilience'; $29 \%$ as 'high impact-recovery'; $8 \%$ as 'moderate impactmoderate symptoms'; and $2 \%$ as 'chronic dysfunction'.

Typically, studies in the resilience literature examine the psychological response to a single particular event (or type of event), often using small case-study samples. Some illustrations of the breadth of events studied are: bereavement, divorce (Mancini et al., 2011), chronic pain (Zhu et al., 2014), disability (McGiffin et al., 2019), injury (Quale and Schanke, 2010; Bonanno et al., 2012), the 9/11 New York attack (Bonano et al., 2006, 2007; Norris et al., 2009), mass shootings (Norris and Stevens, 2007; Reifels et al., 2013), floods (Norris et al., 2009), oil spills (Lee et al., 2018), droughts (Arouri et al., 2015), volcanic events (Paton et al., 2011), earthquakes (Hogg et al., 2016), epidemics (Rao and Greve, 2017) and community violence (O'Donnell et al., 2002). Many studies have focused on the resilience of war veterans (Pietraz et al., 2009; Tsai et al., 2015; Portnoy et al., 2018). This means that any conclusions made about the distribution of resilience are likely to be context- (and potentially sample-) specific, and therefore difficult to generalise to a population distribution. This is important because an individual's psychological response may differ by the nature of the life event, being resilient in some aspects of life, but not others. By focusing on the psychological response to ten major events using nationally representative data, we aim to provide a more general picture of the heterogeneity of resilience in the population.

A distinct but related literature has focused on measures of subjective wellbeing rather than mental health conditions. In particular, researchers have looked at variation in life satisfaction and 
hedonic adaptation to life events, with concepts of the hedonic treadmill and set-point theory ${ }^{7}$ being proposed to explain the "general propensity of human beings to return to a set-point of well-being relatively quickly after even the most aversive or auspicious life events" (Mancini et al., 2011). ${ }^{8}$ In the economics literature, Clark et al. (2008a) and Clark (2016) provide detailed reviews of research on adaptation, with particular emphasis on the role of reference points (e.g. colleagues, peers, or an individual's own past). These studies have tended to analyse large nationally representative panel surveys to illustrate life satisfaction profiles or trajectories, with particular attention on adaptation to income, unemployment and disability. Because of the availability of long panels, Australia (Frijters et al., 2011; Buddelmeyer and Powdthavee, 2016), Britain (Oswald and Powdthavee, 2008; Clark and Georgellis, 2013), and Germany (Clark et al., 2008b; Vendrik, 2013; Qari, 2014), have been the focus of much of this literature. This literature shows clear evidence of adaptation to major events, and in many cases full adaptation, but this is not always the case. Using an individual fixed effects panel model with leads and lags, Clark et al. (2008b) found full adaptation (i.e. a return to baseline satisfaction) to marriage, divorce, widowhood, birth of a child, and layoff within five years for both men and women, but a longer lasting adverse effect on life satisfaction of unemployment for men. Using a similar model, Frijters et al. (2011) found near full adaptation within two years for most major life events. Recent research by Clark et al. (2016) using German panel data found little evidence of adaptation within a poverty spell.

Importantly, these studies focus only on the conditional-mean response to life events, rather than the extent of heterogeneity that we address in this paper. In the conclusion of their study, Clark et al. (2016) call for more research on heterogeneous responses, including analysis by socioeconomic background and personality types. In the psychological literature, Bonanno et al. (2015) similarly note, "Average-level scores typically fail to capture heterogeneity in longitudinal distributions, and, more important, fail to identify resilient trajectories or other longitudinal patterns that bear little resemblance to the average pattern of change."

In a theoretical contribution, Graham and Oswald (2010) propose a theory of hedonic adaptation and resilience to explain how individuals recover psychologically from adverse events. In their model, individuals have a stock of hedonic capital that they can invest in themselves or have invested in by others (e.g. parents, schools, communities, government), for example through socially positive activities (e.g. spending time with friends; undertaking charitable works). This hedonic capital is drawn upon to cope with adverse events, potentially becoming depleted when a sequence

\footnotetext{
${ }^{7}$ See Brickman and Campbell (1972), Lykken and Tellegen (1996), Diener et al. (1999, 2006), Lucas et al. (2003, 2004); Lucas $(2005,2007)$ and Mancini et al. (2011).

${ }^{8}$ Another related literature explores the extent of variability in adult subjective wellbeing. For example, Lucas and Brent Donnellan (2007) find that around 35\% of the variance in life satisfaction is trait variance that does not change over time, with an additional 29-34\% accounted for by a moderately stable component (also see Fujita and Diener, 2005).
} 
of adverse events occurs, which then triggers large psychological losses and lower wellbeing. In contrast, the framework of Cunha and Heckman (2009) points to resilience as a non-cognitive trait, or a skill that can be invested in early in life but which is relatively stable in adulthood.

In one of the few empirical economics papers on resilience, Powdthavee (2014) asks: do childhood characteristics predict psychological resilience to economic shocks in adulthood? Using British panel data, he finds that the effect of unemployment on mental health and life satisfaction is significantly less adverse for individuals who during adolescence had a good relationship with their father or an unemployed mother. Two recent papers focus on using locus of control as a measure of resilience. ${ }^{9}$ Buddelmeyer and Powdthavee (2016) use Australian panel data (also HILDA) to investigate whether the effect of adverse events differs for adults by locus of control. They estimate individual random effects and fixed effects models of life satisfaction and mental health, finding that having an internal locus of control acts to moderate the reduction in life satisfaction and/or mental health after negative events, particularly when a close family member is detained in jail. Similarly, Schurer (2017) uses German panel data finds, using tobit and probit models, that having a high locus of control significantly predicts men's ability to remain in the labour force following a health shock. Neither of these two papers examine the relationship between childhood socioeconomic circumstances and adulthood resilience. Together with this focus, later in the paper we will also examine the strength of the relationship between our measure of psychological resilience and locus of control, and other cognitive and non-cognitive traits. ${ }^{10}$ There is also a related literature on the extent to which families, local communities, and social networks informally insure individual consumption and wellbeing against negative events (see, for example, Gertler and Gruber, 2002; Clark and Lelkes, 2005; Dehejia et al., 2007). In particular, Dehejia et al. (2007) find that individuals who attend religious services are better able to insure against income shocks.

\section{Empirical strategy and econometric methods}

Our empirical strategy has three main stages. First, we develop a dynamic finite mixture model to identify individual heterogeneity in the observed fluctuations in psychological health that follow major adverse life events. Second, we derive an individual measure of resilience based on total

\footnotetext{
${ }^{9}$ Locus of control is constructed from questions asked to individuals about their own beliefs about themselves. An example of questions asked in HILDA used to form the measure are: on a 0-7 scale reflecting the strength to which indviduals agree with the statements, "I have little control over the things that happen to me", "There is really no way I can solve some of the problems I have", "There is little I can do to change many of the important things in my life", "I often feel helpless in dealing with the porblems of life", "Sometimes I feel that I'm being pushed around in life", "What happens to me in the future mostly does not depend on me", and "I cannot do just about anything I really set my mind to do" (Cobb-Clark et al., 2014).

${ }^{10}$ Like Schurer (2017), but also the various papers reviewed by Conti et al. (2019), we see reslience as a skill largely developed in childhood, where the effects are (i) lower amplitude following negative events and, (ii) faster adaptation after negative events. We discuss this more later in the paper.
} 
psychological loss from a "standardised event" (SE). Third, we investigate the correlations of this measure of psychological loss (resilience) with clinical measures of mental health, cognitive and noncognitive personality traits, and childhood characteristics and circumstances.

\subsection{Modelling the dynamics of psychological health}

Before introducing our main model of psychological health, we discuss a standard dynamic model in which the effects of adverse events are presumed to be identical for all individuals:

$$
H_{i t}=\rho H_{i t-1}+\beta^{\prime} x_{i t}+\mu S_{i t}+\delta_{i}+\tilde{\varepsilon}_{i t}
$$

where $S_{i t}$ is a vector of major adverse events, $x_{i t}$ is a set of socioeconomic variables that control for current life circumstances, $\delta_{i}$ is an individual effect, and $\tilde{\varepsilon}_{i t}$ is a serially uncorrelated error term. Lagged psychological health captures the lasting effect of past events on current psychological health, discounting all adverse events at the same exponential rate, $\rho$. In this model, psychological health follows a first-order Markov process, whereby psychological health at $t$ is independent from psychological health at $t$-2, and from past life events, past observed covariates and past time-varying shocks, conditional on psychological health at $t-1$, life events and observed covariates at $t$, and individual time-invariant heterogeneity. Our specification is consistent with previous empirical studies that focused on the impact of lagged adverse events and the extent to which individuals adapt over time (see, for example, Clark et al., 2008b; and Frijters et al., 2011). A point of difference, however, is that instead of including lags of the event variables (e.g. $\left.S_{i t-1}, S_{i t-2}, S_{i t-3}\right)$ in a static model, we include lagged psychological health. This is similar to the approach taken by Pudney (2008), in which a dynamic specification is used to model individuals' subjective assessments of their financial wellbeing. Pudney (2008) interprets the presence of the lagged dependent variable in terms of partial adjustment of perceptions to changes in current life circumstances.

Our model builds on this standard model by adding heterogeneity in the anticipation of and response to major life events through the introduction of random coefficients, and by allowing the error-term variance to be individual-specific:

$$
\begin{aligned}
& H_{i t}=\rho_{i} H_{i t-1}+\beta^{\prime} x_{i t}+\mu_{i 0}{ }^{\prime} S_{i t}+\mu_{i 1}{ }^{\prime} S_{i t+1}+\delta_{i}+\exp \left(\sigma_{i}\right) \tilde{u}_{i t} \\
& \tilde{u}_{i t} \sim \text { i. i.d normal }(0,1)
\end{aligned}
$$

where the coefficients $\rho_{i}, \mu_{i 0}, \mu_{i 1}, \delta_{i}$ and $\sigma_{i}$ are individual effects. The immediate impacts of events on psychological health are represented by the parameter vector $\mu_{i 0}$, while the anticipation effects are captured by $\mu_{i 1}$. This specification controls for selection into life events on fixed unobserved 
heterogeneity, and we only assume that conditional on $\delta_{i}$, life events randomly befall on individuals. We thus control for non-random selection into life events, under the particular assumption that the occurrence of life events after $t+1$ is independent from psychological health at $t$, conditional on life events occurring at $t$ and $t+1$, observed covariates at $t$, and $\delta_{i}{ }^{11}$

The empirical literature documenting the impact of life events on wellbeing has largely focused on adaptation (post-event) profiles, but Clark et al. (2008b) and Frijters et al. (2011), and others, have shown that wellbeing also changes prior to the occurrence of events. They have found that the events with the strongest anticipation effects are those that are understandably predictable, such as divorce. In our model, the individual-specific anticipation parameter $\mu_{i 1}$ measures the impact of all information relevant to future events that the respondent has already received. Observed future events are thus included as proxy variables for this information.

Importantly, Equation (2) allows individuals to differ along four key dimensions: (1) baseline level of psychological health due to unobserved time-invariant factors as accounted for by $\delta_{i}$ : this can be interpreted as an individual set-point to which a person returns in the long run, but is included to capture any heterogeneity in levels that is constant over the data period (we refrain from interpreting its determinants causally); (2) anticipation and immediate (short-term) reactions to each adverse event, as accounted for by the parameter vectors $\mu_{i 0}$ and $\mu_{i 1}$; (3) average adaptation trajectories, as captured by $\rho_{i}$, with a higher $\rho_{i}$ implying slower adaptation; and (4) unobserved events that may vary in frequency and magnitude across individuals, as accounted for by $\sigma_{i}$, which captures unobserved volatility in psychological health. ${ }^{12}$

The dynamic nature of equation (2) means that we face an initial condition problem, because the first observed level of psychological health could be correlated with the individual effects. We overcome this issue by conditioning on initial psychological health $H_{i 0}$, specifying a Mundlak-type relationship between the individual effect $\delta_{i}$ and the covariates:

$$
E\left[\delta_{i} \mid H_{i 0}, S_{i}, x_{i}\right]=\alpha_{i}+\lambda w_{i}
$$

\footnotetext{
${ }^{11}$ This then excludes specific sequences, for instance the case where a depression at $t$ increases the probability of divorce at $t+2$, even after controlling for other life events occurring at $t$ and $t+1$. As we chose to work with a large set of life events, it was clearly not possible to model and identify the probabilities of occurrence of all the life events. This would have required the identification of $2^{10}-1$ probabilities of transition, and therefore the availability of many unrelated exclusion restrictions to identify these probabilities.

${ }^{12}$ An alternative empirical strategy would be to model psychological health as a function of a set of variables representing adverse life events, a set of lag and lead variables for each event (to capture anticipation and adaptation), a set of variables for childhood circumstances and personality traits, and all of the interactions among the sets. However, given the large number of variables in each set, a fully specified model would include hundreds of variables. In practice, to make such a model tractable and interpretable would require a sequential selection process of the relevant interaction variables with a high probability of misspecification. In addition, preliminary regressions reveal that this approach is plagued by problems of near multi-collinearity. The more parsimonious model in equation (2) has the added advantage of having a more natural interpretation.
} 
where $S_{i}$ and $x_{i}$ are row vectors of all explanatory variables in all time periods, $\alpha_{i}$ is an individual individual random effect, and $w_{i}=\left(H_{i 0}, \bar{S}_{i t}, \bar{x}_{i t}\right)$. We also assume that $\left(\rho_{i}, \mu_{i}, \sigma_{i}\right)$ are independent of the covariates. Our measure of individual heterogeneity in adaptation to life events (resilience) will not reflect individual ability to affect the occurrence of events (self-selection). ${ }^{13}$ The parameter vector $\Theta_{\mathrm{i}}=\left(\rho_{i}, \mu_{i}, \alpha_{i}, \sigma_{i}\right)$ is distributed according to a joint density function $f\left(\Theta_{i}\right)$ that can be factored into a conditional distribution $g\left(\alpha_{i}, \sigma_{i}, \rho_{i} \mid \mu_{i}\right)$ and a marginal distribution $h\left(\mu_{i}\right)$.

\subsection{A finite mixture dynamic model}

We assume that $g$ and $h$ are finite discrete distributions. ${ }^{14}$ We therefore let the marginal density $h$ be represented by a finite number $C$ of points $\left\{\mu_{1}, \mu_{2}, \ldots, \mu_{C}\right\}$ with associated mass probabilities $\left\{p_{1}, p_{2}, \ldots, p_{c}\right\}$. Hence:

$$
\operatorname{Pr}\left(\mu_{i}=\mu_{c}\right)=p_{c}, \sum_{c=1}^{C} p_{c}=1
$$

Letting $\theta_{i}=\left(\alpha_{i}, \sigma_{i}\right)$, the conditional distribution $g\left(\theta_{i}, \rho_{i} \mid \mu_{i}\right)$ is represented by a bivariate discrete distribution with $K_{c} \times L_{c}$ support points $\left\{\left(\theta_{k c}, \rho_{l c}\right) ; k=1, \ldots, K_{c} ; l=1, \ldots, L_{c}\right\}$ and associated mass probabilities $\left\{\pi_{k l c} ; k=1, \ldots, K_{c} ; l=1, \ldots, L_{c}\right\}$ :

$$
\operatorname{Pr}\left(\theta_{i}=\theta_{k c}, \rho_{i}=\rho_{l c} \mid \mu_{i}=\mu_{c}\right)=\pi_{k l c}, \sum_{k=1}^{K_{c}} \sum_{l=1}^{L_{c}} \pi_{k l c}=1
$$

The literature often takes a 'latent class' interpretation of these distributional assumptions ${ }^{15}$, whereby the heterogeneity of the population results from the mixing of several populations (classes) that may differ in their short-term $\left(\mu_{c}\right)$ and long-term $\left(\rho_{l c}\right)$ reactions to life events, and in the baseline level and volatility of psychological health $\left(\theta_{k c}\right)$. With individual class membership unobserved, these population classes are latent. We view this 'latent class' interpretation of the model as a convenient way to discuss the estimation results. Notably however, the latent classes only capture 'ideal' types of psychological response profiles, with all individuals lying somewhere between these ideal classes.

\footnotetext{
${ }^{13}$ The assumption of independence between $\left(\rho_{i}, \mu_{i}, \sigma_{i}\right)$ and $\left(H_{i 0}, S_{i}, x_{i}\right)$ could be relaxed. But this would come at the price of introducing many interaction terms between the covariates, and therefore losing all the benefits of mixture models.

${ }^{14}$ We have chosen discrete distributions for the parameters instead of continuous multivariate distributions to gain in flexibility, to minimize specification biases - discrete distributions can approximate any continuous distribution - and to avoid having to use simulated maximum likelihood techniques with high-dimensional integrals.

${ }^{15}$ For instance, Clark et al. (2005) present their model in terms of latent classes, rather than using the more general term "finite mixture". A similar presentation has often been used in the empirical literature on health care use (Deb and Trivedi, 2002) or consumption (Wedel et al., 1993; Etilé, 2006).
} 
Our ultimate aim is to identify individual profiles of responses to adverse events through a mixture of these types.

Conditional on time-invariant membership in a latent class indexed by $\{c, k, l\}$, the dynamics of psychological health are assumed to be represented correctly by the following model with nonrandom and fixed coefficients:

$$
\begin{aligned}
H_{i t} & =\rho_{l c} H_{i t-1}+\beta^{\prime} x_{i t}+\mu_{0 c}{ }^{\prime} S_{i t}+\mu_{1 c}{ }^{\prime} S_{i t+1}+\lambda w_{i}+\alpha_{k c}+\exp \left(\sigma_{k c}{ }^{\prime}\right) \tilde{u}_{i t} \\
\tilde{u}_{i t} & \sim \text { i. i.d normal }(0,1)
\end{aligned}
$$

We observe the empirical probabilities $\operatorname{Pr}\left(H_{i 1}, \ldots H_{i T} \mid S_{i}, x_{i}, H_{i 0}, w_{i}, z_{i}\right)$, where $S_{i}$ denotes the set of anticipated and contemporaneous adverse events. Given our modelling assumptions, we have the following decomposition of the individual contribution to the sample likelihood:

$$
\begin{aligned}
& \operatorname{Pr}\left(H_{i 1}, \ldots H_{i T} \mid S_{i}, x_{i}, H_{i 0}, w_{i}\right) \propto \\
& \sum_{c=1}^{C} p_{c} \sum_{k=1}^{K_{c}} \sum_{l=1}^{L_{c}} \pi_{k l c}\left[\prod_{t=1}^{T} \operatorname{Pr}\left(H_{i t} \mid H_{i t-1}, x_{i t}, S_{i t}, S_{i t+1}, w_{i}, \Theta_{i}=\left(\rho_{l c}, \mu_{c}, \theta_{k c}\right), \beta, \lambda\right)\right]
\end{aligned}
$$

This decomposition result stems in particular from the first-order Markov condition of no autocorrelation in the error term and independence between psychological health at $t$ and $t-2$ conditional on psychological health at $t-1$, the contemporaneous values of the covariates (life events at $t$ and $t+1$ ), and the values of the individual random effects. Given independence between the random effects and the error term $\tilde{u}_{i t}$, the probability in brackets follows a normal distribution. Denoting the standard normal p.d.f by $\phi$, the parameters $\rho_{l c}, \mu_{c}, \theta_{k c}, \beta, \lambda$ are obtained via maximisation of the following log-likelihood:

$$
\sum_{i} \ln \left(\sum_{c=1}^{C} p_{c} \sum_{k=1}^{K_{c}} \sum_{l=1}^{L_{c}} \pi_{k l c}\left[\prod_{t=1}^{T} \phi\left(\frac{H_{i t}-\rho_{l c} H_{i t-1}-\beta^{\prime} x_{i t}-\mu_{0 c}^{\prime} S_{i t}-\mu_{1 c}^{\prime} S_{i t+1}-\lambda^{\prime} w_{i}-\alpha_{k c}}{\exp \left(\sigma_{k c}^{\prime} z_{i}\right)}\right)\right]\right)
$$

Importantly, this finite mixture dynamic model allows individuals with similar short-term responses to adverse events to have different speeds of adaptation: the correlation between the distribution of $\rho_{i}$ and the distribution of $\mu_{i}$ is not restricted a priori. In addition, the dependence between heterogeneity in response profiles, and the heterogeneity in levels and unobserved volatility of psychological health, is left unrestricted. This would not have been the case if we had restricted the distribution of $\theta_{i}=$ $\left(\alpha_{i}, \sigma_{i}\right)$ to have only one support point (i.e. we do not impose $K_{c}=1$ for all $\left.c\right) .{ }^{16}$ As such, we will

\footnotetext{
${ }^{16}$ This constraint, which is almost always imposed in empirical applications of latent class models, would imply that all healthy individuals show little reaction to adverse events, while all unhealthy individuals are very reactive (or vice versa).
} 
identify resilience heterogeneity from individual patterns of reactions to the adverse events specified in $S_{i t}$, not from the size of unobserved shocks captured by $\sigma_{i}$.

\subsection{Identification, estimation and model selection}

The parametric model associated with the likelihood function in equation (8) is identified from standard results on the identifiability of finite mixtures of Gaussian laws. ${ }^{17}$ Proving the nonparametric identification of the mixture components in a more general model with a totally flexible error term is beyond the scope of this paper. Nevertheless, Kasahara and Shimotsu (2009) show that finite mixture models of dynamic discrete choice are identified when at least six periods of observation are available, when there is enough variation in the covariates, and when the response pattern of different individuals to similar variations in covariates is truly heterogeneous. In our case, identification also relies on the observation of different patterns of responses to adverse events by individuals with similar observed characteristics (in particular, similar initial level of psychological health and similar probabilities of adverse events over the observation period). The length of the observation period is key to empirical identification, because it allows us to observe similar individuals with different time sequences of adverse events. Between-individual variations in these sequences help to identify the individual heterogeneity in the distribution of the dynamics of psychological health.

The model likelihood in (8) is highly non-linear and has many parameters, and so is difficult to maximise directly. We therefore apply the iterative EM (Expected Maximisation) algorithm of Dempster and Laird (1977). The intuition underlying this algorithm is that the model would be easier to estimate if individual class membership were perfectly observed: we would just need to estimate linear regression models for each class. Because class membership is unobserved, we have a standard problem of missing data. The EM algorithm solves this problem through a two-step procedure. In the E-step, expectations of class membership probabilities are constructed for each individual, using all of the information from the data and the model. Then, in the M-step, linear regression models can be estimated for each class, with each individual observation being weighted by the expected class membership probability. The EM algorithm alternates between these two steps until convergence to a maximum. We carefully conducted several replications of the maximisation using different sets of starting values in order to detect the global maximum of the likelihood function. We compute the

To relax this constraint, we increase the number of classes, but restrict the slope parameters to be similar across some classes. We then have subsets of classes with similar slope coefficients, but different intercepts. Also, unrestricting the potential number of intercept classes gives us more flexibility in modelling the correlated random effect $\delta_{i}$.

${ }^{17}$ See Lindsay (1983) for results on the parametric identification of mixtures of exponential laws. Note that the model is parametrically identified only using the first two waves. 
matrix of variance-covariance of the coefficients using Louis formula (Louis, 1982); more details are provided in Appendix B.

One practical issue is the optimal number of support points $C,\left\{K_{c} ; c=1, \ldots, C\right\}$ and $\left\{L_{c}\right.$; $c=1, . . C$ \}, which is a priori unrestricted. Estimating all possible models would have required prohibitively large computing time. Our ultimate goal is to find distinctive resilience profiles, while controlling as well as possible for unobserved heterogeneity in baseline psychological health. We thus restricted our attention to models with a small number of slope classes $\left(C=2\right.$ or $C=3$, and $L_{c}=1$ or $L_{c}=2$ ) but a high number of support points for the intercept (with an equal number of intercept classes within each slope class). For $C=2$ and $L_{1}=L_{2}=1$, we estimated variants with $K_{c}$ ranging from 1 to 8 support points. For $C=2$ and $L_{1}=1, L_{2}=2$, we estimated variants with up $K_{c}$ ranging from 1 to 6 support points. For $C=3$, we did not allow for additional heterogeneity in the autoregression parameter ( $L_{1}=L_{2}=L_{3}=1$ ), and there are up to $K_{c}=6$ support points. The total number of support points therefore varies from two to $18 .{ }^{18}$ Adding additional support points for the intercept of the slopes generated problems for locating a global maximum with no significant informational gains, and the mass associated with these points tended to be close to zero. We then applied a Bayesian Information Criterion (BIC) to choose between models (McLachlan and Peel, 2000). It is computed as BIC= $-2 * L(k)+k * \ln (n)$ where $L(k)$ is the likelihood of the model, $k$ is its number of parameters and $n$ is the number of observations. Eventually we retained a specification with $C=3$ and $L_{1}=L_{2}=L_{3}=1$, and $K_{1}=K_{2}=K_{3}=6$. Appendix B provides additional details regarding the inference procedure and the selection of the specification.

\subsection{Measuring resilience as psychological loss}

After estimating the finite mixture dynamic model, we derive individual-specific values of the parameters that govern individual differences in psychological responses to life events. We then construct individual measures of resilience, and examine how they correlate with measures of cognition and personality, and then with variables that describe childhood circumstances.

To formalise resilience, we first define a measure of 'Total Psychological Loss' (TPL) for a set of standardised events $S_{. t}=s$ occurring at time $t$. A natural choice for the standardised events is the average in the sample, i.e.s $=\overline{S_{i t}}$. For any individual, $T P L$ then equals:

$$
T P L_{i}(s)=-\sum_{s=t-1}^{+\infty}\left(H_{. s}\left(., S_{. t}=s, \tilde{u}_{. t}=0 ; \rho_{i}, \mu_{i}\right)-H_{. s}\left(., S_{. t}=0, \tilde{u}_{. t}=0 ; \rho_{i}, \mu_{i}\right)\right)
$$

\footnotetext{
${ }^{18}$ Our approach is therefore a mix between standard applications of latent class models that focus on the identification of a small number of distinct profiles, and econometric papers that view finite mixture distributions as a flexible means of modelling unobserved heterogeneity, and estimate models with large number of support points (see Train, 2008, Bonhomme and Robin, 2009). See Etilé and Sharma (2015) for a similar approach applied to the heterogeneity in consumer price response.
} 
where $H_{. s}\left(., S_{. t}=s, \tilde{u}_{. t}=0 ; \rho_{i}, \mu_{i}\right)$ denotes the psychological health of an individual whose life trajectory is only changed with respect to the events that happened in period $t .{ }^{19} T P L$ measures interindividual differences in the undiscounted lifetime impact of adverse events, holding constant the probability of experiencing adverse events. Given the linear nature of our model, TPL is independent of any other characteristics or history and collapses to a simple formula:

$$
T P L_{i}(s)=-\frac{\left(\mu_{i 0}+\mu_{i 1}\right) s}{1-\rho_{i}}
$$

Individual values for $T P L$ can be obtained by using the estimated model coefficients. To see how it works, note that for each individual $i$ we can compute the set of posterior probabilities from the model estimates:

$$
\begin{aligned}
& p_{i c l}=\operatorname{Pr}\left(\rho_{i}=\rho_{l c}, \mu_{i}=\mu_{c} \mid H_{i 1}, \ldots H_{i T}, S_{i}, x_{i}, H_{i 0}, w_{i}, \beta, \lambda\right) \\
& =\sum_{k=1}^{K_{c}} \operatorname{Pr}\left(\rho_{i}=\rho_{l c}, \mu_{i}=\mu_{c}, \theta=\theta_{k c} \mid H_{i 1}, \ldots H_{i T}, S_{i}, x_{i}, H_{i 0}, w_{i}, \beta, \lambda\right) \\
& =\sum_{k=1}^{K_{c}} \frac{p_{c} \pi_{k l c} \operatorname{Pr}\left(H_{i 1}, \ldots H_{i T} \mid S_{i}, x_{i}, H_{i 0}, w_{i}, \rho_{i}=\rho_{l c}, \mu_{i}=\mu_{c}, \theta=\theta_{k c}, \beta, \lambda\right)}{\operatorname{Pr}\left(H_{i 1}, \ldots H_{i T} \mid S_{i}, x_{i}, H_{i 0}, w_{i}, \beta, \lambda\right)}
\end{aligned}
$$

These membership probabilities then can be used to construct expected individual values for $T P L$, conditional on the available information:

$$
T P L_{i}^{*}(s)=E\left(T P L_{i}(s) \mid H_{i 1}, \ldots H_{i T}, S_{i}, x_{i}, H_{i 0}, w_{i}, \beta, \lambda\right)=\sum_{c=1}^{C} \sum_{l=1}^{L_{c}} p_{i c l} T P L_{l c}\left(s ; \rho_{l c}, \mu_{c}\right)
$$

where $T P L_{l c}\left(s ; \rho_{l c}, \mu_{c}\right)$ is a measure of TPL for resilience class $\{c, l\}$ :

$$
T P L_{l c}\left(s ; \rho_{l c}, \mu_{c}\right)=-\frac{\left(\mu_{c 0}+\mu_{c 1}\right) s}{1-\rho_{l c}}
$$

\footnotetext{
${ }^{19}$ Here, resilience is about reactions to negative life events. The minus sign is set to yield a scale taking positive values, as the psychological impact of negative life events is negative a priori. The unobserved shocks are set to 0 , because we want to avoid any influence of the variance $\sigma_{i}$, which captures volatility due to both positive and negative shocks.
} 
In a second step, we can estimate the extent to which childhood characteristics predict resilience. ${ }^{20}$ In these regressions, TPL is standardised using the standard deviation of psychological health

\subsection{Discussion}

The above outlined modelling approach is similar to empirical methods from the existing 'latent class' literature in economics and psychology, including economics studies that have modelled heterogeneity in the relationship between income and wellbeing (Clark et al., 2005; Brown et al., 2014), and psychology studies that have modelled heterogeneity in the dynamics of psychological health after a major life event (see, for example, Galatzer-Levy and Bonanno, 2012; Mancini et al., 2011; Galatzer-Levy et al., 2011; Galatzer-Levy et al., 2010; Kariuki et al., 2011; and Bonanno et al., 2012). However, our work differs from these studies in three main ways. First, we identify individual psychological response profiles that are common to a large set of commonly experienced major adverse life events; this strengthens the identification of resilient individuals and avoids restricting the sample to individuals affected by a single specific type of event, potentially introducing sample selection bias. Our identification, based on the psychological response to ten commonly experienced life events, is also more general and wide-ranging than studies that have focused on the psychological response to particular natural disasters, technological shocks, and terrorist attacks.

Second, we do not presume a priori that individuals belong to only one latent class. Rather, we suppose that each class represents an 'ideal type' of profile defined by the same levels of $\left\{\rho_{i}, \mu_{i 0}, \mu_{i 1}\right\}$. However, if individuals are well-classified into the different classes ( $p_{i l c}$ is close to 1 or 0 ), then the class-specific measures of resilience and the individual-specific measure in (14) will provide similar results. If the classification is fuzzier, with many individuals having ex-post probabilities $p_{i l c}$ far from 0 and 1 , then the individual-specific measure we identify is a more efficient tool for examining the correlations between resilience and childhood circumstances. The latter turns out to be clearly the case in our application.

Third, we control for unobserved fixed heterogeneity in the baseline and variance of psychological health. Therefore, our resilience measure is derived from a within-individual approach to adaptation, rather than population-level statistics based on cross-sectional variations in psychological health that mix individual levels of psychological health with the frequency of events

\footnotetext{
${ }^{20} \mathrm{We}$ do not estimate this second step as an integral part of the latent class modeling of the dynamics of psychological health, because we want to avoid imposing strong priors on the nature of the correlates of resilience. In this second-step regression, the dependent variable is a complex and non-linear functional form of the first-stage estimates. This introduces heteroskedasticity in the regressions. We therefore apply a White correction in all of our second-stage regressions (White, 1980). More efficient techniques that are advocated in the context of linear transformations of first-stage estimates cannot be used here (Hanushek, 1974, Saxonhouse, 1976). Consequently, our second-step results will tend to yield overestimated standard errors.
} 
and their impact on individuals. Because we use a vector of standardised events for the calculation of $T P L$, individual differences in resilience do not reflect variations in occurrences of adverse events. This clearly delineates two different targets for policy intervention and evaluation: on the one hand, individual resilience, and on the other, occurrences of adverse events.

\section{Data}

\subsection{The Household, Income and Labour Dynamics in Australia (HILDA) Survey}

We use data from the HILDA Survey, a nationally representative longitudinal study of Australian households that began in 2001. Wave 1 began with a sample of 19,914 panel members from 7,682 households. In each year since, members of these households have been followed-up, along with new household members that result from changes in the composition of the original households, and new households from the Wave 11 top-up sample. Our data are from 2001 to 2017, with each wave providing detailed information on a wide-range of economic, social, health and demographic information.

We use HILDA because it is the only dataset including all the information needed for our empirical approach. In particular, it includes: questions asked in every wave about whether respondents' experienced a wide range of major life events in the last twelve months; respondents are followed over a long enough period of time for us to be able to capture anticipation and adaptation; a detailed and consistent health survey is conducted in every wave (i.e. the SF-36 questionnaire); we know whether individuals have a diagnosed mental health condition, and whether they are taking medication; respondents have been tested on their cognitive ability (Wave 12); personality traits have been collected through the Big-5 Personality Inventory (Waves 5, 9, 13 and 17) and a locus of control questionnaire (Waves 3, 4, 7,11 and 15); and respondents are asked retrospective questions about their childhood circumstances, including measures of their socioeconomic status and health. The retrospective questions on childhood and all demographic and socioeconomic information are collected through face-to-face interviews, while information on life events, health, and personality, are collected through a confidential self-completion questionnaire. Importantly, we are unaware of any other panel survey that contains all of this required information.

We focus on respondents who were aged 25 to 69 in their first survey. We start at age 25 because we want to identify individuals' intrinsic resilience and its association with childhood circumstance, rather than the contemporaneous effects of family material and psychological support. For instance, heterogeneity in young adults' psychological response to an adverse event (e.g. being fired or made redundant) may be driven by the level of direct support received from parents (e.g. financial, housing) rather than by differing levels of resilience. We also exclude those individuals observed for less than eight consecutive periods, a sufficient time period to observe the full adaptation 
profile of most adverse events, and the time we find is required for the within-individual variance in psychological health to stabilise (results available upon request). Finally, we exclude observations with missing information on the adverse event variables. Given that the adverse event questions are not included in Wave 1 of HILDA, this restriction implies that equation (1) is estimated using information from Waves 2-17. However, Wave 1 psychological health is used to address the initial conditions problem (as noted in Section 2.2). These combined restrictions leave us with the main estimation sample of 6,294 individuals and 69,460 individual-period observations.

\subsection{Measuring psychological health}

Psychological health is a latent variable that we measure using information from the Short-Form General Health Survey (SF-36), which is incorporated in many surveys and asks respondents a widerange of questions about their health. Let $H_{i t}$ denote the true latent psychological health of individual $i$ at time $t$, and assume $H_{i t}$ is related to a set of $K$ survey indicator variables $I_{i t}^{1}, \ldots, I_{i t}^{K}$ by a measurement function $\mathcal{M}$ :

$$
\left(I_{i t}^{1}, \ldots, I_{i t}^{k}\right) \rightarrow H_{i t}=M\left(I_{i t}^{1}, \ldots, I_{i t}^{k}\right)
$$

Following international guidelines (Ware, 2000), the measurement function $\mathcal{M}$ is a factor analysis model of the eight health dimensions of the SF-36. These eight dimensions are constructed by a weighted summation of answers to items on the SF-36 and cover the main domains of health: physical functioning, physical role functioning, bodily pain, general health perception, vitality, social functioning, emotional role functioning and mental health. The factor analysis uses only the first observation of each individual in the full sample of HILDA, and produces a two-component representation: the first component summarises psychological health (eigenvalue equals 2.394) and the second component summarises physical health (eigenvalue equals 2.060). Column 1 of Table A1 in Appendix A reports the factor loadings of each of the eight dimensions on the psychological health component. The second column reports the coefficients of the linear equation used to predict the psychological health component after orthogonal Varimax factor rotation. These coefficients show that psychological health primarily reflects four dimensions of the SF-36: mental health, emotional functioning, social functioning, and vitality. The psychological health component is normalised to have a mean of 50 and a standard deviation of 10 in the full HILDA sample, yielding the psychological health observations used to estimate equation (1). ${ }^{21}$

\footnotetext{
21 Note that simultaneously estimating the measurement model and the finite mixture dynamic model for latent psychological health is not feasible. Pudney (2008) applies a simulation method for estimating a dynamic model of subjective wellbeing similar to (1), wherein the measurement model is specified with ordered probit models. This involves
} 
Figure 1 shows a histogram of psychological health for the estimation sample. The distribution has a mean of 51.2 and a standard deviation of 9.48. It is negatively skewed (skewness equals -1.2) and leptokurtic (kurtosis equals 4.4). While the vast majority of individuals are in good psychological health, $10 \%$ of the observations have scores lower than 38 , and $5 \%$ of the observations have scores lower than 32 .

\subsection{Ten major adverse life events}

As noted earlier, a key advantage of the HILDA survey is that in every wave (starting in wave 2) respondents are asked about the occurrence of major life events (in a section of the confidential selfcompletion questionnaire). This section is completed after the SF-36 health questionnaire, so respondents' recollection of life events should not bias their evaluation of their psychological health. Respondents are told, "We now would like you to think about major events that have happened in your life over the past 12 months", and then are asked to indicate whether each of the listed events happened and how long ago. ${ }^{22}$ The list has 21 life events, but we focus in this paper on the following ten more commonly experienced adverse events: (1) "major worsening in financial situation (e.g. went bankrupt)"; (2) "fired or made redundant by an employer"; (3) "separation from spouse or longterm partner"; (4) "death of spouse or child"; (5) "death of other close relative / family member (e.g. parent or sibling)"; (6) "death of a close friend"; (7) "serious personal injury or illness to self"; (8) "serious personal injury or illness to a close relative / family member"; (9) "victim of physical violence (e.g. assault)"; and (10) "victim of a property crime (e.g. theft, housebreaking)".

Table 1 provides descriptive characteristics for each of these events, with $96 \%$ of respondents reporting at least one of them in the panel window, a median of four events and $15 \%$ having eight events or more. Moreover, we have a non-trivial number of occurrences for each of these events, with 'serious injury/illness to family member' being the most common, occurring in 16.4 percent of the year-person observations, or once every 6 years for the average individual. This is followed in frequency by 'death of a relative / family member' and then 'death of a close friend', which are reported in around 11 percent of the year-person observations. A major worsening of finances, being fired or made redundant, being a victim of property crime, and becoming separated from spouse or longer-term partner are all reported by around 2 to 4 percent of cases. As expected, the least common

simulating integrals of dimension equal to the number of observation periods plus one, so the data is restricted to six periods. In our case, the identification of individual heterogeneity in parameters requires that a maximum number of periods be used. In addition, the estimation and the selection of latent class models rely on an iterative EM algorithm, with the maximisation of likelihood functions at each step (see the technical appendix).

${ }^{22}$ While respondents also are asked about the timing of these adverse events in terms of 3-month periods (0-3 months ago, 4-6 months ago, etc.), we follow the bulk of the literature in aggregating these into yearly events. 
events are 'death of spouse/child' and 'victim of physical violence', with less than one percent of the sample reporting such an event.

\subsection{Childhood and adulthood sample characteristics}

Table 1 also shows the average of the contemporary (proximal) adulthood covariates used in our analyses. The average age of the sample is $51 ; 47$ percent of observations are male; and 47 percent are employed full-time, with around 2 percent being unemployed. Just under one-third (28 percent) have a university degree-level education, the log of annual household income is 11.08; 78 percent are married or cohabitating; and the average number of dependent children is 0.60. Additionally, we present descriptive statistics for the cognitive and non-cognitive (personality) traits, as well as alternative clinical-related indictors of psychological health, which we use later to inform the resilience measure. Importantly, one-in-ten of the observations in our sample report a current diagnosis of depression and/or anxiety; around 5 percent are taking prescription medication(s) for these conditions; and just under 6 percent report having seen a psychiatrist or psychologist in the past year.

In various waves of HILDA, the respondents are asked retrospective questions about their childhood circumstances, with the reference point being age 14 . The questions relate to their family structure, broad socioeconomic characteristics, and their childhood health status. The variables we use to examine the extent to which childhood characteristics predict adulthood resilience are shown in Table 2. On average, respondents report having 2.8 siblings (the median is about 2, with a long tail); 8 percent immigrated to Australia before the age of 14; and about 1 percent had their mothers, and $8 \%$ their fathers, absent from the family household due to divorce. Similarly, by age 14 , for 1 percent of respondents their mother had died, and for around 4 percent their father had died. Just under half of the respondents (48 percent) report that their mother was employed, and the statistics for fathers' occupation show that our sample respondents come from a wide range of broad socioeconomic backgrounds. About 40 percent had a father working in managerial or professional occupations; and on the other end of the occupational scale, about 22 percent of fathers were machine operators, drivers and labourers. In terms of childhood health, the majority of respondents (58 percent) report having been in excellent health at age 14 , but just over $5 \%$ report having been in only fair or poor health.

Although we would prefer to have information that covers the entire of childhood, the measures do relate to the important teenage years and are likely easier for the adult respondent to recall than earlier childhood. Moreover, given the strong persistence in household socio-economic status (Aaronson and Mazumder, 2008) we expect that our socioeconomic measures (at age 14) will be highly correlated with early childhood circumstances. 


\section{Results}

\subsection{Psychological response to major adverse events}

Our main results are presented in Table 3. Column 1 shows the estimates from a dynamic random effects (DRE) model that controls for initial conditions but only provides information about the average response to events, because there is no heterogeneity in coefficients (see Equation 1 with the same parameters for all individuals). The results from this initial model are informative and appear reasonably intuitive. First, the coefficient on lagged psychological health (0.225) tells us that, for the sample as a whole, there is a fairly low level of persistence over time. Second, all of these major adverse events are associated with a significant immediate decline in psychological health. As expected, the effects are large for death of a spouse or child (-2.808), separation from spouse or partner (-2.325), injury or illness to self (-2.362), and being a victim of violent crime (-1.963). Interestingly, the second largest immediate decline in psychological health, after the death of a spouse or child, arises from a major worsening of financial situation, such as a bankruptcy (-2.772). In contrast, there is only a relatively small immediate response from having been fired or made redundant (-0.336). The model also reveals that many of these adverse events are anticipated before their actual occurrence. The largest anticipation effects occur for separation from spouse or partner (1.404) and death of spouse or child (-1.121). The economic events major financial worsening (-0.691) and being fired or made redundant (-0.311) are also anticipated. In contrast, the only events for which we find no significant evidence of anticipation effects are death of a close relative, or death of a close friend.

Results from our preferred specification (Equation 2) are shown in Columns 2-4 in Table 3. This model captures heterogeneity in psychological response by identifying three distinct slope 'classes' of individuals, each describing about one-third of our sample (the split is $38.3 \%, 30.1 \%$ and $31.6 \%$ ). It is clear from the estimates that this model allows for greater insight into how individuals differ in their responses to commonly experienced adverse events. The event variables were all significant in the DRE linear model, but these estimates reflect average effects and hide considerable heterogeneity in the population. In particular, it is clear that the coefficients on the event variables are much larger for Class 3 than for Class 2, and to a lesser extent (but not in all cases) are higher for Class 2 than for Class 1. For instance, the immediate effect of a separation from spouse or partner equals -5.223 for Class $3,-0.257$ for Class 2 , and -0.250 for Class 1 . We also find large differences in the speed of adaptation between the three classes. The effect of previous psychological health is markedly higher for Class $2(0.470)$ than for Classes 1 (0.101) and $3(0.137)$. These estimates imply that adaptation is nearly complete within one year for Class 1 and 3, with events having a half-life of around one year. The return to a baseline level of psychological health takes considerably longer for Class 2, with the reduction in psychological health after one and two years equalling $53 \%$ and $29 \%$ 
of the immediate drop, respectively. Notably, the small coefficients on the lag of psychological health for two out of the three classes relative to the dynamic random-effect linear model estimate of 0.225 , suggests that we have adequately controlled for individual heterogeneity in this model. Important unobserved heterogeneity would be reflected by large coefficients on the lagged psychological health variable.

The relative sizes of the estimated adverse event coefficients are in line with expectations. For Class 3, the death of a spouse or child is the worst event that we measure, with an immediate substantive drop (-9.946) in psychological health. Furthermore, experiencing a major financial worsening, separation from a spouse or partner, and own serious illness or injury, are all estimated to reduce psychological health by about a half-standard deviation in the short term $(-5.327,-5.223$, 5.500). For Class 3 the coefficients on the lead event variables $\left(S_{t+1}\right)$ are largest for events that conceivably could be anticipated: the effect is significant for separation from spouse or partner (1.998), death of spouse or child (-1.789), and injury or illness to self (-1.036).

In contrast to these results, the estimates for Classes 1 and 2 are generally smaller and often statistically insignificant. Importantly though, these two Classes of individuals do react differently to life events. For Class 1, only a major financial worsening (-0.474), death of a close relative (-0.184), injury or illness to self $(-0.253)$ and being a victim of property crime $(-0.555)$, are linked to a significant decline in psychological health. In fact, it is only for this class where we see a negative effect of property crime. Similarly, only for Class 1 do we see a small positive increase in response to being fired or made redundant, in complete contrast to the decline experienced (-1.068) by those in Class 3. Interestingly, for Class 1 we see a drop in psychological health in anticipation (-0.902) of a death of a spouse or child, but this effect is smaller (-0.547) on impact. In contrast, individuals in Class 2 experience have a larger reaction to a major financing worsening (-0.932), death of spouse or child (-1.373), death of a close friend (-0.435), own injury to illness (-1.190), injury or illness of a relative (-0.499), and being a victim of physical violence (-1.543) than those in Class 1 . It is only for being a victim of property crime that the psychological loss is larger at impact for individuals in Class $1(-0.555)$ than Class 2 (0.318). Class 2 also experience larger anticipation effects for own injury to illness than Class $1 .^{23}$

Importantly, it is unlikely that these results are capturing differential levels of event severity rather than actual resilience, because it is hard to argue that (our worst event) deaths of a spouse or

\footnotetext{
${ }^{23}$ The control variable coefficients in our finite mixture model, shown in Appendix Table A2, are difficult to interpret because they are related to the probability of belonging to each of the three classes and the initial conditions variables. However, they do suggest a much weaker relationship betwen adulthood household income and resilience. From the reduced-form results in Column 1, however, we see that this data displays familiar effects of control variables: males, younger individuals, higher income individuals, employed individuals, and couples with few children have better psychological health.
} 
child, or death of a close relative (e.g. parents), is objectively any more severe in nature for some individuals than others.

In the second half of Table 3 we present the estimation results for the intercept $\alpha_{k c}$ and error variance parameters $\sigma_{k c}$ that are specific to each of the 27 latent classes $\{c, k\}$. These parameters account for individual heterogeneity in the baseline level of psychological health from unobserved fixed factors, as well as for unobserved shocks that may vary in size and impact across individuals. These estimates and the estimated autoregressive parameter $\rho_{l c}$ fully characterise the heterogeneity in the process governing the dynamics of psychological health. Intuitively, the dynamics will depend on the importance of state-dependence on the one hand and on the frequency and impact of observed and unobserved shocks on the other hand.

We interpret these results by comparing the three slope classes indexed by $c$ with a focus on the intercept-variance classes $\{k, c\}$ that weigh more than $1 \%$ in the finite mixture distribution (probability weight $\pi_{k c}>1 \%$ ). Class 1 ( $c=1$, first column) generally has higher values for the six intercept parameters, and the estimated variance parameters are much lower than the raw variance of psychological health, which is normalised to equal 10. Since Class 1 individuals also have a low estimated autoregressive parameter, it represents the dynamics of psychological health that are characterised by little state dependence and small fluctuations around high baseline levels. In contrast, Class $2(c=2)$ has the lowest estimated intercept parameters, and its variance parameters vary from 1.85 for $c=2$ and $k=1$ to 11.236 for $c=2, k=3$. The autoregressive parameter $\rho$ is close to 0.5 , so Class 2 captures the dynamics of psychological health that display large state-dependence and potentially large fluctuations from unobserved shocks. Class $3(c=3)$ has higher intercept estimates than slope class 2, and larger estimates of the variance parameters $(11.38$ for $c=3$ and $k=3 ; 8.48$ for $c=3$ and $k=7) .{ }^{24}$ The estimated autoregressive parameter is low, implying that slope Class 3 represents a type of dynamics with little state-dependence and large fluctuations produced by unobserved shocks. Although the three slope classes eventually characterise different types of dynamics, there is still important heterogeneity within each slope class, as seen in the estimated intercept and variance parameters. This demonstrates the importance of separately modelling the heterogeneity in state dependence and the heterogeneity in unobserved shocks. In particular, two individuals may be similar in their ability to cope well with adverse events (little state-dependence), but they may still differ with regards to the impact of observed or unobserved events that they experience.

\footnotetext{
${ }^{24}$ A convenient way of comparing the three classes is to predict the intercept and variance values of individuals in each 'slope class'. The average variance is 3.97 in Class 1, 4.93 in Class 2 and 6.45 in Class 3, while the average intercept is 33.3 in Class 1, 9.81 in Class 2, and 28.64 in Class 3.
} 


\subsection{Graphical illustrations of response heterogeneity}

Figure 2 displays the extent of response heterogeneity by summarising the coefficients on the different intercepts and variances shown in Table 2. The left-side graph in Figure 2 shows the densities of psychological health for all of the different combinations of classes, intercepts, and variances, representing all of the possible shapes of the psychological health distribution that we allow via the finite mixture distributions. The bold curve represents the aggregate, empirical distribution of psychological health. In the second graph in Figure 2, we weight these different densities by the estimated relative probability weights of each combination, showing that extreme distributions with density near the tails have low weights, and therefore are less important in making up the whole population.

To illustrate how the coefficients on the lagged psychological health variable and the adverse life events collectively determine the psychological responses to different events, Figure 3 shows the response profiles for each of the Classes for a 'standardised event' (SE) - this is calculated as the occurrence-weighted average of all ten events (see equations (9) and (13) in Section 2.4). In Appendix Figure A1, we also provide the psychological response profiles by Class separately for each event. In terms of the SE, these profiles suggest that despite Class 3 adapting much faster than Class 2, the cumulative total drop in psychological health is greater for Class 3 because of its relatively large immediate negative response. The profiles also show that Class 2 has the second largest cumulative drop in psychological health, driven not by large immediate responses but rather by slower adaptation. The magnitudes of these psychological responses are moderate - the immediate response for Class 3 is around 10 percent of a standard deviation of psychological health. However, Figure 3 presents the occurrence-weighted average response for the ten events, including 'death of a friend', 'injury and illness to a relative' and 'victim of property crime', which are relatively common but estimated to have small impacts on psychological health (see Appendix Figure A1).

Figure 4 further demonstrates the extent of heterogeneity in the total pyschological loss (TPL) associated with a SE (see equation (13) in Section 2). Approximately 10 percent of the sample is estimated to experience a loss totalled across all periods of only around 0.05 units of standardised psychological health (corresponding to 5 percent of a standard deviation). Approximately 6 percent of the sample is estimated to experience a loss of around 0.25 units ( 25 percent of a standard deviation). The dynamic finite mixture model thus predicts substantive differences between the most resilient and least resilient individuals in our sample. Appendix Figure A2 presents the total pyschological loss associated with each event separately, similarly demonstrating the significant level of heterogeneity across individuals, but also demonstrating the significant variation across the different types of adverse events. 


\subsection{Relationship between psychological resilience and clinical measures of mental health}

Table 4 shows the relationship between total psychological loss (TPL) following a SE and three clinically-related measures of mental health. Here we have split the distribution of TPL into terciles, with Tercile 1 being the most resilient individuals, and Tercile 3 being the least resilient. The differences are substantive with individuals in Tercile 3 having over 6 times, 8 times, and 5 times, higher likelihood of currently being diagnosed with depression and/or anxiety, currently taking prescription medication for depression and/or anxiety, and having seen a psychiatrist or psychologist in the past year, respectively, than the most resilient (Tercile 1). Notably, these very strong correlations remain after controlling for demographic characteristics, such as age, gender and educational attainment.

\subsection{Is resilience distinct from cognitive ability and personality?}

In Table 5 we investigate the correlation between estimated psychological resilience and measures of cognitive ability and personality (see Appendix C for details ). Our measure of resilience is a person's predicted percentile in the total psychological loss (TPL) distribution. Naturally, it ranges from 1 the lowest percentile of the TPL distribution (highest resilience) - to 100 - the highest percentile of TPL (lowest resilience).

Studies in the psychology literature have identified high intelligence as being predictive of resilience in the face of adversity (Martinez-Torteya et al., 2009). Consistent with this literature, we find in Column 2 of Table 5 that cognitive ability is positively and significantly associated with being more resilient i.e. experiencing a smaller psychological loss from major adverse events. Moving from the bottom (10th percentile) to the top (90th percentile) of the cognitive ability distribution (an approximate 2.5 unit movement), is estimated to reduce a person's percentile in the TPL distribution by around 7.5. Interestingly, the inclusion of cognitive ability eliminates the significant effect of having a university degree shown in Column 1.

A number of economic studies have found that having an external locus of control is associated with lower human capital and poorer labour market outcomes (see, for example, Cebi, 2007; Caliendo et al., 2015; Schurer, 2017; Lekfuangfu et al., 2018). Importantly, in terms of interpreting these traits, Cobb-Clark and Schurer (2012, 2013), also using HILDA data, found evidence of high stability of locus of control, and Big-Five personality traits, over a four-year period in adulthood. They argue that these traits are exogenous to major life events. In contrast, Elkims et al. (2017) find that these traits change through adolescence and young adulthood. With this in mind we find that an external locus of control positively and significantly related to having lower psychological resilience (higher TPL) following an adverse event. In fact, locus of control has the strongest relationship with our resilience measure. This seems reasonable given that a higher internal 
locus of control, which has been used as a measure of resilience, characterises individuals own beliefs about the extent that they can control of events that affect their lives. The magnitude of the locus of control coefficient equals 5.912. This implies that moving from high internal locus of control to high external control (10th to 90th percentile) is associated with a movement in the TLP distribution of almost 15 percentiles of the TPL distribution. We therefore provide some support to previous studies that have used locus of control as a measure of resilience.

Finally, four of the Big-5 personality traits are significantly related to TPL, with agreeableness being the exception. But, the associations are far smaller than was estimated for locus of control. One standard deviation increases in extraversion, conscientiousness, and emotional stability are linked to $1.5,0.9$, and 3.8 percentile decreases in the TPL distribution, respectively. Conversely, openness is associated with a small decrease in resilience (1.3 percentiles).

Overall, these intuitive correlations between resilience and cognitive ability and personality indicate that our resilience measure correctly captures differential responses to adverse events. However, the correlations are modest in magnitude, but greatest for locus of control, and the Rsquared value in the largest regression (column 3 ) is only 0.104 . Therefore, the results suggest that our estimated resilience measure is largely an independent construct from cognitive ability and personality. ${ }^{25}$

\section{Childhood predictors of adulthood psychological resilience}

Here we explore the extent to which adulthood resilience is predicted by childhood socioeconomic characteristics. While there still exists some debate about whether psychological resilience is fixed after childhood, or rather a dynamic process that moves in response to different types of life events, here we assume that resilience is a fixed trait. This is akin to the findings of Cobb-Clark and Schurer $(2012,2013)$ for locus of control and personality. We add to a psychology literature that has found that low resilience is correlated with a diverse range of childhood factors, including poverty, parental mental illness, poor parenting, maltreatment, neglect, abuse, and the experience of violence (Luttar et al., 2000; Martinez-Torteya et al., 2009).

HILDA respondents have been asked to recall aspects of their childhood, including their family composition, parental education and occupational status, and their health as a child. ${ }^{26}$ Within

\footnotetext{
${ }^{25}$ In a similar exercise Becker et al. (2012) examine the strength of the relationship between economic preferences (time and risk) and personality (Big-5) and find only low correlations, suggesting that they are complements and cannot be used as substitutes.

${ }^{26}$ Importantly, we are unaware of any longitudinal survey that contains all of the information (i.e. life events) and properties (i.e. a long annual panel) that we need to estimate our main model, and collects more detailed information on specific childhood adversities. Surveys such as the UK National Child Development Study (NCDS), the US National Longitudinal Survey of Youth (NLSY) and the US National Longitudinal Study of Adolescent to Adult Health (Add Health) have asked respondents to recall adversities from their childhood, but the long period between surveys would not
} 
a framework where more educated and wealthier parents' choose to, and are able to, provide greater investment in building their children's resilience (thought of as a non-cognitive skill) we might expect that, on average, children from low SES households will have lower resilience in adulthood (Cunha et al., 2010; Conti et al., 2019). Similarly, we might think that having poor health in childhood could hinder such skill development.

Table 6 presents the results from models of resilience that use this retrospective data. First, using the full sample is a simple linear regression of TPL percentile on childhood characteristics (column 1). Second, we present estimates separately by gender (column 2 and 3). Overall, our model has some explanatory power in predicting adulthood resilience. The significant coefficient estimates suggest that males are on average more resilient than females, that resilience increases with age, and that there is a socioeconomic gradient as measured by father's occupation. In particular, adults whose fathers worked in low-skilled occupations (i.e. labourers, machine operators or drivers) are significantly less likely to be resilient, or in other words, have a higher total psychological loss following a standardised event.

By far the strongest predictor of resilience in adulthood that we identify is childhood health. In comparison to a childhood of 'excellent' health, having 'very good' health reduces a person's resilience percentile by 3 . This movement increases to 6 percentiles, 11 percentiles, and 16 percentiles, respectively, for 'good', 'fair', and 'poor' health. A change from poor to excellent childhood health therefore has a similarly sized association as a change from high external LOC to high internal LOC. If we additionally include controls for cognitive ability and personality in this model, the strong relationship between childhood health and adult resilience remains. However, we are cautious about over emphasising this finding for two reasons. First, we cannot rule out that childhood health itself might partially be reflecting early life resilience. Second, it is possible that part of the strong relationship is explained by retrospective bias in the reporting of childhood health. It is possible that certain adverse events in adulthood may 'change' the way in which an adult recollects their childhood circumstances., However, to the extent that childhood health is capturing true differences between respondents, then the finding of a strong childhood gradient in adult resilience provides additional support for the case of public investment in health in the early years of life (see Case et al., 2005).

allow for the identification of psychological loss (resilience) as we have been able to do; we would not observe the timing of life events very well, and anticipation and full adaptation to life events likely would be unobserved between survey waves. 


\section{Conclusion}

A key focus of many Governments is to strengthen the resilience of their people, communities and businesses. In this paper we have provided new evidence on the distribution of resilience, which we model as a fixed trait in adulthood. The topic of resilience is important for economists to study, because it is essential to identify the mechanisms that promote recovery from disadvantage (Cunha and Heckman, 2009), by understanding who in the population needs more help, and which types of life events are the severest (Clark, 2016); and whether there is a clear link between resilience on the one hand and well-being, and the potential high economic costs of mental illness on the other hand (Asheim et al., 2019). A recent highprofile review published in Nature Human Behaviour states that, "There is a pressing need for prospective longitudinal resilience studies", where resilience is defined as, "The maintainance or quick recoevery of mental health during and after exposure to significant stressors (which) results from a dynamic process of adaption to the given stressful life circumstances" (Kalisch et al., 2017). This is exactly what we provide in this paper.

By studying resilience, we are also contributing to the recent economics literature that focuses on the childhood development of non-cognitive skills, and how these types of skills impact on economics outcomes. However, this is no easy task because psychological resilience is not directly observable and requires conceptual and methodological assumptions. We have applied an empirical methodology that we believe measures psychological resilience and captures the extent of heterogeneity in the population, and we have used the best available panel data to do so. The finite mixture modelling techniques we use, that build on previous research in psychology and economics (for example, Clark et al., 2005; Bonanno et al., 2010; Mancini et al., 201; Brown et al., 2014), captures and informs on the extent of heterogeneity in the psychological response to life's adverse major events. In particular, we have fitted a flexible model that allows for individual heterogeneity in anticipation, contemporaneous impact, and adaptation speed, to ten major life events over 16 waves of panel data. Importantly, the model controls for the initial conditions problem, and the fact that individuals are not randomly allocated to experience life events.

However, while we control for these factors, we cannot make any strong causal claims. This is because this would require an instrument for each of the 10 major life events we study, and we would argue that focusing on the causal effect of any one event using a single quasi-natural experiment for identification (whilst informative about that particular event) would not allow us to meet our objective of characterising the more general distribution of resilience. Nor do we expect that resilience can be measured well in experimental laboratory settings, as individuals need to be observed over many years before and after a wide range of major life events.

The dynamic finite mixture model predicts large differences between the most resilient and least resilient individuals in our sample, with large differences in both the immediate psychological 
response to events and in the speed of adaptation. We find support for our measure of resilience in the strength of its relationship with experienced mental health conditions: our measure of psychological resilience is strongly correlated with being diagnosed with depression or anxiety, taking medication for depression or anxiety, and having seen a psychiatrist or psychologist in the last year. In particular, those who are estimated to be the least resilient are seven times more likely to be currently diagnosed with depression or anxiety than those estimated to be the most resilient. Further, we show that our resilience measure captures a different construct to cognitive ability, locus of control, and the Big-5 personality traits. We find that resilience is significantly correlated with these measures, in plausible directions, but they predict little of the variation in resilience.

Further research would be needed to more fully understand the dynamics interaction of these traits with resilience. In particular, a growing literature in economics has focused on locus of control (for example, Cobb-Clark and Schurer, 2013), which is the degree to which people believe that they, as opposed to external forces, have control over the outcome of events in their lives (Rotter, 1966). While locus of control has been used as a measure of resilience, our results suggest that the correlation between our measure of resilience, based on how individual react to 10 major life events, and locus of control is moderate, but it is likely that they will have similar developmental origins.

We do find evidence that broad socioeconomic circumstances in childhood are predictive of psychological resilience in adulthood, as would be predicted from a model where more wealthy parents invest greater financial and/or time resources in the development of their children's noncognitive skills (Cunha et al., 2010). In particular, we find that children who had a father working in unskilled or low skilled occupations have lower adult resilience than children of professionals and managers; though the size of these differences is not large. More notably, we find that childhood health status is the strongest predictor of future resilience, with poor childhood health being associated with significantly lower psychological resilience. This result is supportive of a wider literature in economics that emphasises the importance of tackling early life inequalities in health, given their long-term socioeconomic consequences (see, for example, Case et al., 2005; Goodman et al., 2011).

The conceptualisation and empirical modelling of psychological resilience is broad and complex, and we believe we provided some advancement to the literature in more fully tackling this complexity. The large number of identifying adverse major life events and the general robustness of the resilience measure makes it unlikely that our results depend much on functional form or the omission of any other life events. Also, it is unlikely that our results pick up differential levels of event severity rather than actual resilience, because the same general response pattern is seen for the worst event we study, death of a spouse or child, and different resilience profiles are found following the death of a parent. It is hard to argue that these events are objectively different for some individuals than others, in a way that would bias our results. 
However, because our study pools lots of events and different groups, the methodology may not fully capture rare-group behaviour. Thus, future research might look for heterogeneity in the very tails of the resilience distribution, because public costs in crime and health are often related to behavioural extremes. More generally, we hope that by providing a comprehensive review of the large literature in psychology and linking it with the smaller literature in economics, the paper will encourage other economists to study issues around the importance of psychological resilience. 


\section{References}

Aaronson, D, and Mazumder, B. (2008). Intergenerational economic mobility in the United States, 1940 to 2000. Journal of Human Resources, 43, pp. 139-172.

Afifi, TO. and MacMillan, HL. (2011). Resilience following child maltreatment: A review of protective factors. Canadian Journal of Psychiatry, 56, pp. 266-272.

Amstadter, AB., Myers, JM. And Kendler, KS. (2014). Psychiatric resilience: Longitudinal twin study. British Journal of Psychiatry, 205, pp. 275-280.

Arouri, M., Nguyen. C. and Youssef, AB. (2015). Natural disasters, household welfare, and resilience: Evidence from rural Vietnam. World Development, 70, pp. 59-77.

Asheim, GB., Bossert, W. D'Ambrosio, C. and V"ogele, C. (2019). The measurement of resilience. ECINEQ Working Paper 2019-486.

Banny, AM., Cicchetti, D., Rogosch, FA., Oshri, A. and Crick, NR. (2013). Vulnerability to depression: A moderated mediation model of the roles of child maltreatment, peer victimization, and serotonin transporter linked polymorphic region genetic variation among children from low socioeconomic status backgrounds. Development and Psychopathology, 25, pp. 599-614.

Becker, A., Deckers, T., Dohmen, T., Falk, A. and Kosse, F. (2012). The relationship between economic preferences and psychological personality measures. Annual Review of Economics, 4, pp. 453-478.

Boardman, JD., Blalock, CL. and Button, TMM. (2008). Sex differences in the heritability of resilience. Twin Research and Human Genetics, 11, pp. 12-27.

Bonanno, GA. (2004). Loss, trauma, and human resilience: Have we underestimated the human capacity to thrive after extremely adverse events? American Psychologist, 59, pp. 20-28.

Bonanno, GA., Galea, S., Bucciarelli, A. and Viahov, D. (2006). Psychological resilience after disaster: New York City in the aftermath of the September $11^{\text {th }}$ terrorist attack. Psychological Science, 17, pp. 181-186.

Bonanno, GA., Galea, S., Bucciarelli, A. and Viahov, D. (2007). What predicts psychological resilience after disaster? The role of demographics, resources, and life stress. Journal of Consulting and Clinical Psychology, 75, pp. 671-682.

Bonanno, GA., Brewin, CR., Kaniasty, K. and La Greca, AM. (2010). Weighing the costs of disaster: Consequences, risks, and resilience in individuals, families, and communities. Psychological Science in the Public Interest, 11, pp. 1-49.

Bonanno, GA. (2012). Uses and abuses of the resilience construct: Loss, trauma, and health-related adversities. Social Science and Medicine, 74, pp. 753-756.

Bonanno, GA., Kennedy, P., Galatzer-Levy, IR., Lude, P. and Elfström, ML. (2012). Trajectories of resilience, depression, and anxiety following spinal cord injury. Rehabilitation Psychology, 57, pp. 236-247.

Bonanno, GA., Romero, SA. and Klein, S. (2015). The temporal elements of psychological resilience: An integrative framework for the study of individuals, families, and communities. Psychological Inquiry, 26, pp. 139-169.

Bonhomme, S. and Robin, JM. (2009). Assessing the equalizing force of mobility using short panels: France, 1990-2000. The Review of Economic Studies, 76, pp. 63-92.

Borghans, L., Golsteyn, BH., Heckman, J. and Humphries, JE. (2011). Identification problems in personality psychology. Personality and individual differences, 51, pp. 315-320.

Brown, S., Durand, RB., Harris, MN. and Weterings, T. (2014). Modelling financial satisfaction across life stages: A latent class approach. Journal of Economic Psychology, 45, pp. 117-127.

Buddelmeyer, H. and Powdthavee, N. (2016). Can having internal locus of control insure against negative shocks? Psychological evidence from panel data. Journal of Economic Behavior and Organization, 122, pp. 88-109.

Caliendo, M., Cobb-Clark, DA. And Uhlendorff, A. (2015). Locus of control and job search strategies. Review of Economics and Statistics, 97, pp. 88-103.

Case, A., Fertig, A. and Paxson, C. (2005). The lasting impact of childhood health and circumstance. Journal of Health Economics, 24, pp. 365-389. 
Caspi, A., Sugden, K., Moffitt, T., Taylor, A., Craig, IW., Harrington, HL., McClay, J., Mill, J., Martin, J., Braithwaite, A. and Poulton, R. (2003). Influence of life stress on depression: Moderation by a polymorphism in the 5-htt gene. Science, 301, pp. 386-389.

Cebi, M. (2007). Locus of control and human capital investment revisited. Journal of Human Resources, XLII, pp. 919-932.

Celeux, G., Chauveau, D. and Diebolt, J. (1996). Stochastic versions of the em algorithm: an experimental study in the mixture case. Journal of Statistical Computation and Simulation, 55, pp. 287-314.

Charney, DS. (2004). Psychobiological mechanisms of resilience and vulnerability: Implications for successful adaptation to extreme stress. American Journal of Psychiatry, 161, pp. 195-216.

Cicchetti, D. and Rogosch, FA. (1997). The role of self-organization in the promotion of resilience in maltreated children. Development and Psychopathology, 9, pp. 797-815.

Cicchetti, D. (2012). Annual research review: Resilient functioning in maltreated children - past, present, and future perspectives. Journal of Child Psychology and Psychiatry, 54, pp. 402-422.

Clark, AE., Etilé, F., Postel-Vinay, F., Senik, C. and van der Straeten, K. (2005). Heterogeneity in reported well-being: Evidence from twelve European countries. Economic Journal, 115, pp. C118-C132.

Clark, A.E., Frijters, P. and Shields, MA. (2008a). Relative income, happiness and utility: An explanation for the Easterlin paradox and other puzzles. Journal of Economic Literature, 46, pp. 95-144.

Clark, AE., Diener, E., Georgellis, Y. and Lucas, RE. (2008b). Lags and leads in life satisfaction: A test of the baseline hypothesis. Economic Journal, 118, pp. F222-F243.

Clark, AE. And Georgellis, Y. (2013). Back to baseline in Britain: Adaptation in the British Household Panel Survey. Economica, 80, pp. 496-512.

Clark, AE., D'Ambrosio, C. and Ghislandi, S. (2016). Adaptation to poverty in long-run panel data. Review of Economics and Statistics, 98, pp. 591-600.

Clark, AE. (2016). Adaptation and the Easterlin Paradox. In Advances in Happiness Research: A Comparative Perspective, by T. Tachibanaki (ed.), Chapter 6, Springer.

Cobb-Clark, DA. and Schurer, S. (2012). The stability of big-five personality traits. Economics Letters, 115, pp. 11-15.

Cobb-Clark, DA. and Schurer, S. (2013). Two economists' musings on the stability of Locus of Control. Economic Journal, 123, pp. F358-F400.

Cobb-Clark, DA., Kassenboehmer, SC. and Schurer, S. (2014). Healthy habits: The connection between diet, exercise, and locus of control. Journal of Economic Behavior and Organization, 98, pp. 1-28.

Connor, KM. and Zhang, W. (2006). Resilience: Determinants, measurement, and treatment responsiveness. CNS Spectrums, 11, pp. 5-12.

Conti, G., Mason, G. and Poupakis, S. (2019). Developmental origins of health inequality. IZA Discussion Paper no. 12448, Bonn.

Cunha, F., Heckman, JJ. and Schennach, SM. (2010). Estimating the technology of cognitive and noncognitibve skill formation. Econometrica, 78, pp. 883-931.

Cunha, F. and Heckman, JJ. (2009). The economics and psychology of inequality and human development. Journal of the European Economic Association, 7, pp. 320-364.

Cutter, SL., Ahearn, JA., Amadei, B., Crawford, P. et al. (2013). Disaster resilience: A national imperative. Environment: Science and Policy for Sustainable development, 55, pp. 25-29.

Deb, P. and Trivedi, P.K. (2002) The structure of demand for health care: latent class versus two-part models. Journal of Health Economics, 21, pp. 601-625.

Dempster, AP. and Laird, NM. (1977). Maximum likelihood from incomplete data via the EM algorithm. Journal of the Royal Statistical Society, 39, pp. 1-38.

Diener, E., Suh, EM., Lucas, RE. and Smith, HL. (1999). Subjective well-being: Three decades of progress. Psychological Bulletin, 125, pp. 276-302.

Diener, E., Lucas, RE. and Scollon, CN. (2006b). Beyond the hedonic treadmill: Revising the adaptation theory of well-being. American Psychologist, 61, pp. 305-314. 
Elkins, RK., Kassenboehmer, SC. and Schurer, S. (2017). The stability of personality traits in adolescence and young adulthood. Journal of Economic Psychology, 60, pp. 37-52.

Etilé, F. (2006). Who does the hat fit? Teenager heterogeneity and the effectiveness of information policies in preventing cannabis use and heavy drinking. Health Economics, 15, pp. 697-718.

Etilé, F. and Sharma, A. (2015). Do high consumers of sugar-sweetened beverages respond differently to price changes? A Finite Mixture IV-Tobit approach. Health Economics, 24, pp. 1147-1163.

Fletcher, D. and Sarkar, M. (2013). Psychological resilience: A review and critique of definitions, concepts and theory. European Psychologist, 18, pp. 12-23.

Frijters, P., Johnston, D. and Shields, MA. (2011). Life satisfaction dynamics with quarterly life event data. Scandinavian Journal of Economics, 113, pp. 190-211.

Fujita, F. and Diener, E. (2005). Life satisfaction set point: Stability and change. Journal of Personality and Social Psychology, 88, pp. 158-64.

Galazer-Levy, IR., Bonanno, GA. and Mancini, AD. (2010). From marienthal to latent growth mixture modeling: A return to the exploration of individual differences in response to unemployment. Journal of Neuroscience, Psychology and Economics, 3, pp. 116-125.

Galatzer-Levy, IR. and Bonanno, GA. (2012). Beyond normality in the study of bereavement: Heterogeneity in depression outcomes following loss in older adults. Social Science \& Medicine, 74, pp. 1987-1994.

Goodman, A., Joyce, R. and Smith, JP. (2011). The long shadow cast by childhood physical and mental problems on adult life. Proceedings of the National Academy of Sciences, 108, pp. 60326037.

Graham, L. and Oswald, AJ. (2010). Hedonic capital, adaptation and resilience. Journal of Economic Behavior and Organization, 76, pp. 372-384.

Hogg, D., Kingham, S., Wilson, TM. and Ardagh, M. (2016). The effects of relocation and level of affectedness on mood and anxiety symptom treatments after the 2011 Christchurch earthquake. Social Science and Medicine, 152, pp. 18-26.

Howell, KH. And Miller-Graff, LE. (2014). Protective factors associated with resilient functioning adulthood after childhood exposure to violence. Child Abuse and Neglect, 38, pp. 1985-1994.

Kalisch, R. et al. (2017). The resilience framework as a stragety to combat stress-related disorders. Nature Human Behaviour, November, pp. 784-790.

Kariuki, M., Honey, A., Emerson, E., Llewellyn, G. (2011). Mental health trajectories of young people after disability onset. Disability and Health Journal, 4, pp. 91-101.

Kasahara, H. and Shimotsu, K. (2009). Nonparametric identification of finite mixture models of dynamic discrete choices. Econometrica, 77, pp. 135-175.

Lee, J., Blackmon, BJ., Cochran, DM., Kar, B. and Stubbs Gunnell, M. (2018). Community resilience, psychological resilience, and depressive symptoms: An examination of the Mississippi Gulf Coast 10 years after Hurricane Katrina and 5 years after the Deepwater Horizon oil spill. Disaster Medicine and Public Health Preparedness, 12, pp. 241-248.

Lekfuangfu, WN., Powdthavee, N., Warrinnier, N. and Cornaglia, F. (2018). Locus of control and its intergenerational implications for early childhood skill formation. Economic Journal, 128, pp. 298-329.

Longstaff, PH., Armstrong, NJ., Perrin, K., Parker, WM. and Hidek, MA. (2010). Building resilient communities: A preliminary framework for assessment. Homeland Security Affairs, 6.3, September.

Louis, TA. (1982). Finding the observed information matrix when using the EM algorithm. Journal of the Royal Statistical Society. Series B (Methodological), 44, pp. 226-233.

Lucas, RE., Clark, AE., Georgellis, Y. and Diener, E. (2003). Reexamining adaptation and the set point model of happiness: Reactions to changes in marital status. Journal of Personality and Social Psychology, 84, pp. 527-539.

Lucas, RE., Clark, AE., Georgellis, Y. and Diener, E. (2004). Unemployment alters the set point for life satisfaction. Psychological Science, 15, pp. 8-13. 
Lucas, RE. (2005). Time does not health all wounds: A longitudinal study of reaction and adaptation to divorce. Psychological Science, 16, pp. 945-950.

Lucas, RE. (2007). Adaptation and the set-point model of subjective well-being: Does happiness change after major life events? Current Directions in Psychological Science, 16, pp. 75-79.

Lucas, RE. and Brent Donnellan, M. (2007). How stable is happiness? Using the STARTS model to estimate the stability of life satisfaction. Journal of Research in Personality, 41, pp. 1091-98.

Luthar, SS. and Cicchetti, D. (2000a). The construct of resilience: Implications for interventions and social policies. Development and Psychopathology, 12, pp. 857-885.

Luthar, SS., Cicchetti, D. and Becker, B. (2000b). The construct of resilience: A critical evaluation and guideline for future work. Child Development, 71, pp. 543-562.

Lykken, D. and Tellegen, A. (1996). Happiness is a stochastic phenomenon. Psychological Science, 7, pp. 186-189.

Mancini, AD., Bonanno, GA. and Clark, AE. (2011). Stepping off the hedonic treadmill: Latent class analyses of individual differences in response to major life events. Journal of Individual Differences, 32, pp. 144-152.

Martinez-Torteya, C., Bogat, GA., von Ete, A., and Levendosky, AA. (2009). Resilience among children exposed to domestic violence: The role of risk and protective factors. Child Development, 80, pp. 562-577.

Masten, AS. (2001). Ordinary magic: Resilience processes in development. American Psychologist, 56, pp. 227-238.

Masten, AS. and Powell, JL. (2003). A resilience framework for research, policy, and practice. In SS. Luthar (ed.), Resilience and Vulnerability: Adaptation in the Context of Childhood Adversities, Chapter 1, Cambridge University Press.

Masten, AS. (2007). Resilience in developing systems: Progress and promise as the fourth wave rises. Development and Psychopathology, 19, pp. 921-930.

Maccallum, F., Galatzer-Levy, IR. and Bonanno, GA. (2015). Trajectories of depression following spousal and child bereavement: A comparison of the heterogeneity in outcomes. Journal of Psychiatric Research, 69, pp. 72-79.

McGiffin, JN., Galatzer-Levy, IR. and Bonanno, GA. (2019). Socioeconomic resources predict trajectories of depression and resilience following disability. Rehabilitation Psychology, 64, pp. 98-103.

Netuveli, G., Wiggins, RD., Montgomery, SM., Hildon, Z. and Blane, D. (2008). Mental health and resilience in older ages: Bouncing back after adversity in the British Household Panel Study. Journal of Epidemiology and Community Health, 62, pp. 987-991.

Norris, FH. and Stevens, SP. (2007). Community resilience and the principles of mass trauma intervention. Psychiatry, 70, pp. 320-328.

Norris, FH., Tracy, M. and Galea, S. (2009). Looking for resilience: Understanding the longitudinal trajectories of responses to stress. Social Science and Medicine, 68, pp. 2190-2198.

Orcutt, HK., Bonanno, GA., Hannan, SM. and Miron, LR. (2014). Prospective trajectories of posttraumatic stress in college women following a campus mass shooting. Journal of Traumatic Stress, 27, pp. 249-256.

Oswald, AJ. and Powdthavee, N. (2008). Does happiness adapt? A longitudinal study of disability with implications for economists and judges. Journal of Public Economics, 92, pp. 1061-1077.

Pietrzak, RH., Johnson. DC., Goldstein, MB, Malley, JC. and Southwick, SM. (2009). Psychological resilience and postdeployment social support protect against traumatic and depressive symptoms in soldiers returning from operations enduring Freedom and Iraqi Freedom. Depression and Anxiety, 26, pp. 745-751.

Portnoy, GA., Relyea, MR., Decker, S., Shamaskin-Garroway, A., Driscoll, M., Brandt, CA. and Haskell, SG. (2018). Understanding gender differences in resilience among veterans: Trauma history and social ecology/ Journal of Traumatic Stress, 31, pp. 845-855.

Powdathavee, N. (2014). What childhood characteristics predict psychological resilience to economic shocks in adulthood? Journal of Economic Psychology, 45, pp. 84-101. 
Public health England (2014). Local action on health inequalities: Building children and young people's resilience in schools. Health Equity Evidence Review 2, September, London.

Pudney, S. (2008). The dynamics of perception. Modelling subjective well-being in a short panel. Journal of the Royal Statistical Society: Series A, 171, pp. 21-40.

Rao, H. and Greve, HR. (2017). Disasters and community resilience: Spanish Flu and formation of retail cooperatives in Norway. Academy of Management, 61, pp. 5-25.

Reifels, L., Pietrantoni, L., Prati, G., Kim, Y., Dean. G. et al. (2013). Lessons learned about psychosocial responses to disaster and mass trauma: An international perspective. Journal of Psychotraumatology, 4, pp. 22897.

Rotter, JB. (1966). Generalized expectancies for internal versus external control of reinforcement. Psychological Monographs: General and Applied, 80, pp. 1-28.

Ruhm, CJ. (2019). Shackling the identification police. Presidential Address, Southern Economic Journal, 85, pp. 1016-1026.

Rutter, M. (1985). Resilience in the face of adversity: Protective factors and resistance to psychiatric disorder. British Journal of Psychiatry, 147, pp. 598-611.

Rutter, M. (1987). Psychosocial resilience and protective mechanisms. American Journal of Orthopsychiatry, 57, pp. 316-331.

Seery, MD., Holman, EA. and Silver, RC. (2010). Whatever does not kill us: Cumulative lifetime adversity, vulnerability, and resilience. Journal of Personality and Social Psychology, 99, pp. 1025-1041.

Southwick, SM., Bonanno, GA., Masten, AS., Panter-Brick, C. and Yehuda, R. (2014). Resilience definitions, theory, and challenges: Interdisciplinary perspectives. European Journal of Psychotraumatology, pp. 5.

Schurer, S. (2017). Bouncing back from health shocks: Locus of control and labour supply. Journal of Economic Behavior and Organization, 133, pp. 1-20.

Train, K. E. (2008). EM algorithms for nonparametric estimation of mixing distributions. Journal of Choice Modelling, 1, pp. 40-69.

Tsai, J., El-Gabalawy, R., Sledge, WH., Southwick, SM. and Pietrzak, RH. (2015). Post-traumatic growth among veterans in the USA: Results from the National Health and Resilience in Veterans Study. Psychological Medicine, 45, pp. 15-179.

Vendrik, MCM. (2013). Adaptation, anticipation and social interaction in happiness: An integrated error-correction approach. Journal of Public Economics, 105, pp. 131-149.

Wedel, M., DeSarbo W.S., Bult J.R. and Ramaswamy, V. (1993). A Latent Class Poisson Regression Model for Heterogeneous Count Data. Journal of Applied Econometrics, 8, pp. 397-411. 
Figure 1: Empirical Distribution of Psychological Health

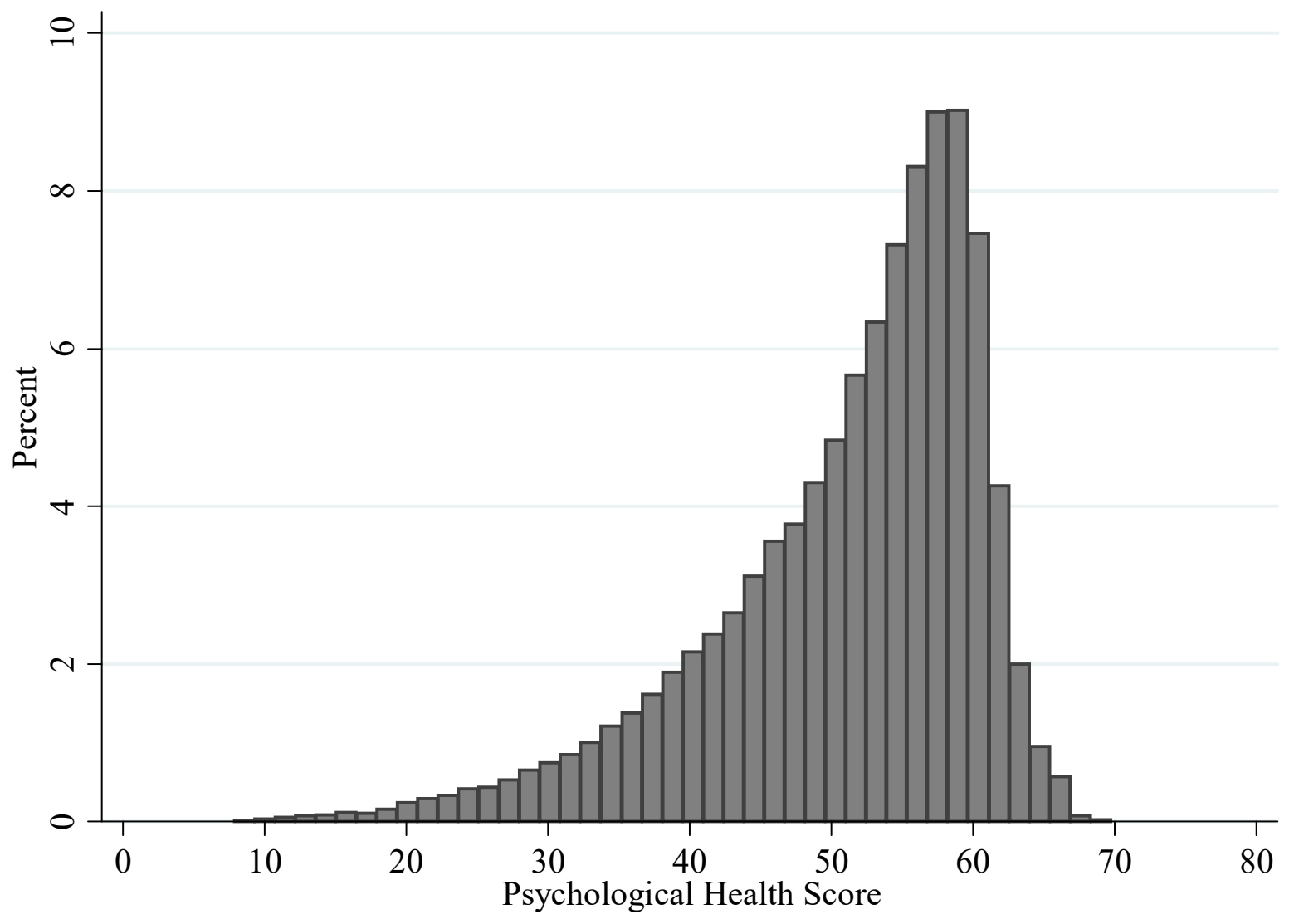


Table 1: Descriptive Statistics for Adulthood Variables

\begin{tabular}{|c|c|c|c|c|}
\hline & Mean & Std. Dev. & Min & Max \\
\hline \multicolumn{5}{|l|}{ Life Events } \\
\hline Major worsening in financial situation & 0.027 & 0.162 & 0 & 1 \\
\hline Fired or made redundant by an employer & 0.026 & 0.160 & 0 & 1 \\
\hline Separated from spouse or long-term partner & 0.023 & 0.151 & 0 & 1 \\
\hline Death of spouse or child & 0.006 & 0.078 & 0 & 1 \\
\hline Death of other close relative / family member & 0.112 & 0.316 & 0 & 1 \\
\hline Death of a close friend & 0.110 & 0.313 & 0 & 1 \\
\hline Serious injury or illness to self & 0.082 & 0.274 & 0 & 1 \\
\hline Serious injury or illness to a close relative & 0.164 & 0.370 & 0 & 1 \\
\hline Victim of physical violence & 0.008 & 0.091 & 0 & 1 \\
\hline Victim of a property crime & 0.036 & 0.185 & 0 & 1 \\
\hline \multicolumn{5}{|l|}{ Contemporary characteristics } \\
\hline Age & 51.18 & 12.17 & 26 & 84 \\
\hline Male & 0.469 & 0.499 & 0 & 1 \\
\hline Employed full-time & 0.467 & 0.499 & 0 & 1 \\
\hline Employed part-time & 0.211 & 0.408 & 0 & 1 \\
\hline Unemployed & 0.017 & 0.131 & 0 & 1 \\
\hline Out of the labour force & 0.304 & 0.460 & 0 & 1 \\
\hline Highest qualification: University degree & 0.281 & 0.450 & 0 & 1 \\
\hline Highest qualification: Vocational diploma & 0.330 & 0.470 & 0 & 1 \\
\hline Highest qualification: High school graduate & 0.102 & 0.303 & 0 & 1 \\
\hline Highest qualification: High school dropout & 0.287 & 0.452 & 0 & 1 \\
\hline Log household income & 11.08 & 0.696 & 7.183 & 14.65 \\
\hline Married or cohabiting & 0.777 & 0.416 & 0 & 1 \\
\hline Divorced or separated & 0.079 & 0.270 & 0 & 1 \\
\hline Single and never married & 0.144 & 0.351 & 0 & 1 \\
\hline Number of children & 0.599 & 0.991 & 0 & 8 \\
\hline \multicolumn{5}{|l|}{ Cognitive ability and personality traits } \\
\hline Cognitive test score (std) & 0.031 & 0.915 & -3.508 & 3.188 \\
\hline External locus of control (std) & -0.014 & 0.951 & -1.423 & 3.870 \\
\hline Extraversion (std) & -0.043 & 1.007 & -3.178 & 2.381 \\
\hline Agreeableness (std) & 0.032 & 0.937 & -4.661 & 1.711 \\
\hline Conscientiousness (std) & 0.113 & 0.971 & -3.965 & 1.860 \\
\hline Emotional stability (std) & 0.040 & 0.975 & -3.696 & 1.662 \\
\hline Openness (std) & 0.028 & 0.960 & -2.984 & 2.598 \\
\hline \multicolumn{5}{|l|}{ Clinical measures of psychological health } \\
\hline Current diagnosed depression / anxiety & 0.108 & 0.310 & 0 & 1 \\
\hline Take depression/anxiety prescription meds & 0.053 & 0.224 & 0 & 1 \\
\hline Seen psychiatrist/psychologist in past year & 0.058 & 0.234 & 0 & 1 \\
\hline
\end{tabular}

Notes: Sample size equals: 6,294 individuals (69,460 individual-waves) for life events, contemporary characteristics, and cognitive ability and personality traits; and 5,721 individuals for clinical measure of psychological health. The cognitive ability and personality trait measures have been standardised to have a mean of zero and a standard deviation of one in the full HILDA sample. 
Table 2: Descriptive Statistics for Childhood Variables

\begin{tabular}{|c|c|c|c|c|}
\hline & Mean & $\begin{array}{l}\text { Std. } \\
\text { Dev. }\end{array}$ & Min & Max \\
\hline Number of siblings & 2.838 & 2.135 & 0 & 18 \\
\hline Immigrate $\leq$ age 14 & 0.078 & 0.269 & 0 & 1 \\
\hline Parents divorced: Mother absent & 0.013 & 0.114 & 0 & 1 \\
\hline Parents divorced: Father absent & 0.077 & 0.266 & 0 & 1 \\
\hline Mother had died & 0.011 & 0.106 & 0 & 1 \\
\hline Father had died & 0.035 & 0.185 & 0 & 1 \\
\hline Lived without both parents & 0.818 & 0.386 & 0 & 1 \\
\hline Mother employed at age 14 & 0.484 & 0.500 & 0 & 1 \\
\hline Father occupation: Manager & 0.256 & 0.437 & 0 & 1 \\
\hline Father occupation: Professional & 0.143 & 0.351 & 0 & 1 \\
\hline Father occupation: Technician / trade & 0.240 & 0.427 & 0 & 1 \\
\hline Father occupation: Community / personal service & 0.032 & 0.177 & 0 & 1 \\
\hline Father occupation: Clerical / administration & 0.064 & 0.244 & 0 & 1 \\
\hline Father occupation: Sales & 0.044 & 0.205 & 0 & 1 \\
\hline Father occupation: Machinery operator / driver & 0.111 & 0.314 & 0 & 1 \\
\hline Father occupation: Labourer & 0.110 & 0.313 & 0 & 1 \\
\hline General health: Excellent & 0.577 & 0.494 & 0 & 1 \\
\hline General health: Very good & 0.247 & 0.431 & 0 & 1 \\
\hline General health: Good & 0.111 & 0.314 & 0 & 1 \\
\hline General health: Fair & 0.040 & 0.196 & 0 & 1 \\
\hline General health: Poor & 0.014 & 0.117 & 0 & 1 \\
\hline
\end{tabular}

Notes: Sample size equals $\mathrm{N}=5,856$ individuals. All of these measures are based on retrospective accounts of childhood from adult HILDA respondents. 
Table 3: Dynamic Random Effect and Finite Mixture Dynamic Models of Psychological Health

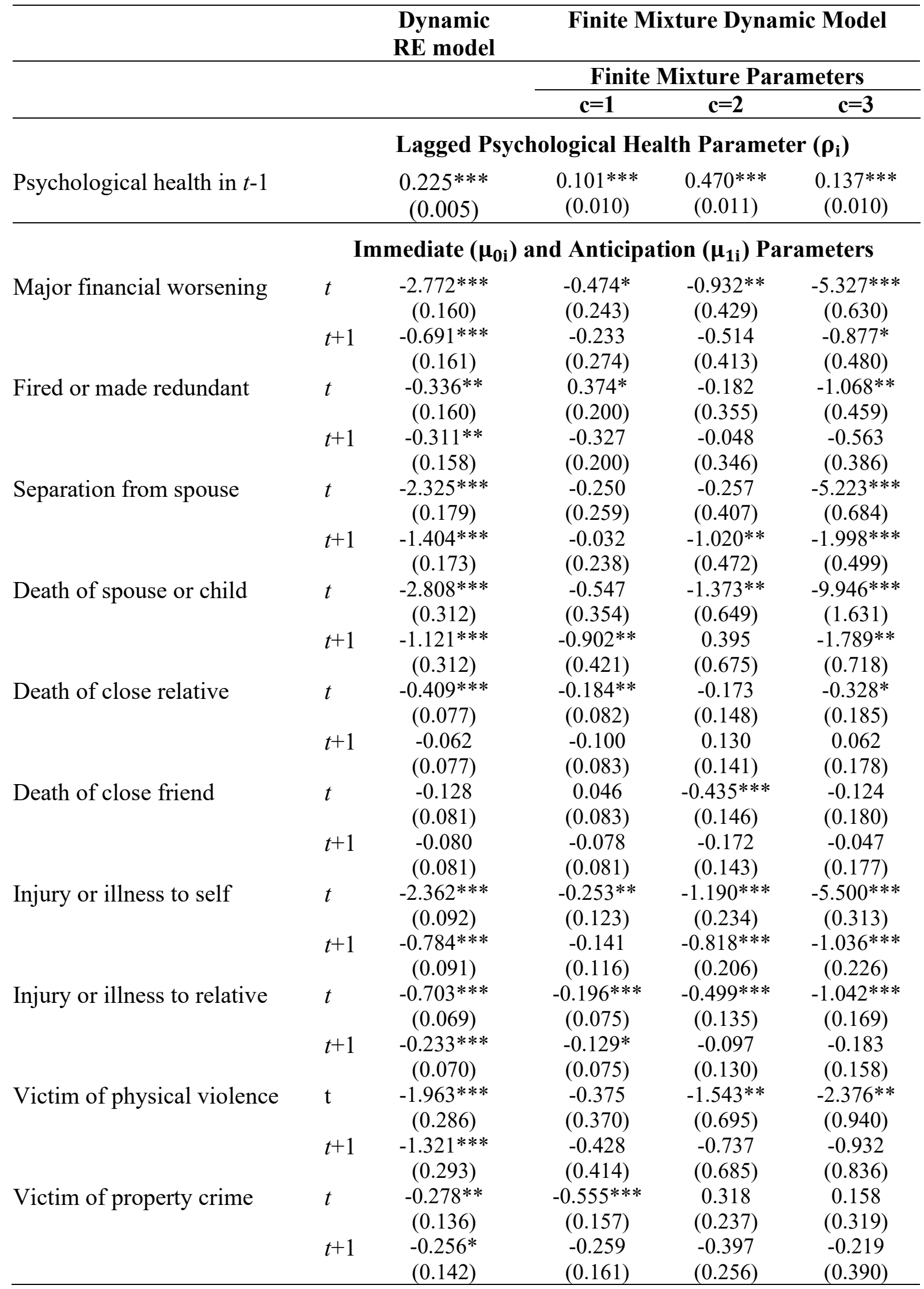


Table 3: (Continued)

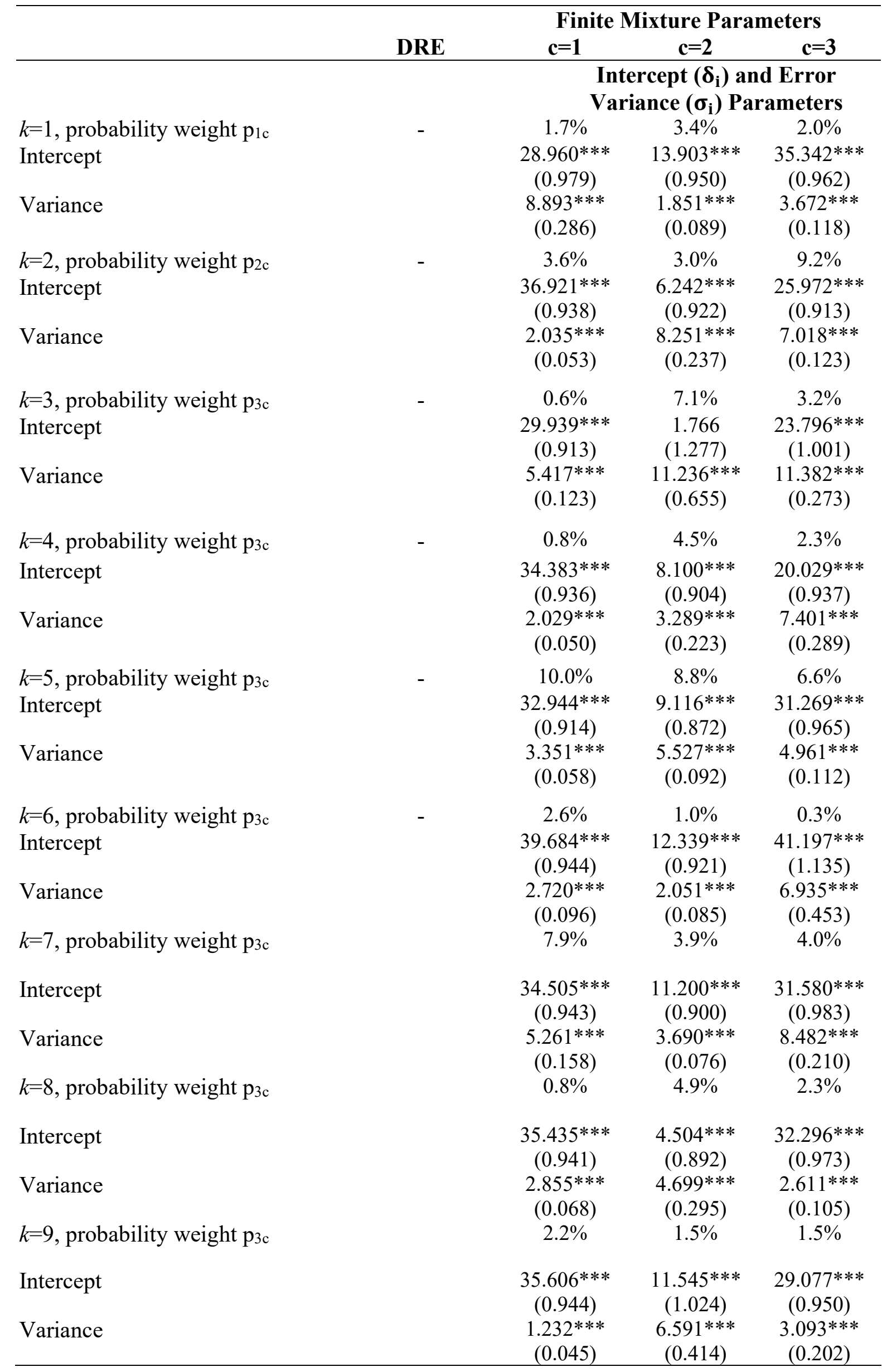


Notes: Column 1 reports results from a dynamic random effects model, where coefficients on lagged psychological health and life events are homogenous. Columns 2-4 report the estimated coefficients of the finite mixture dynamic model for classes 1 to 3 respectively. The upper panel of Table 3 reports the coefficients on lagged psychological health, and contemporaneous and future life events. The lower panel of Table 3 displays the finite mixture paramaters for intercept and variance heterogeneity. In both models, we include as additional control variables with homogenous effects (see Table A2): logarithm of household income, age, age squared, male, labour market status (full-time employment, part-time employment, unemployment, inactive (reference)), degree (university, vocationnal diploma, high-school, less than grade 12 (reference)), marital status (partnered, divorced or separated, single (reference)), number of children at home, year dummies. In both models, we also control for initial conditions by including the initial level of psychological health, as well as the individual average of all time-varying variables. Standard errors in parentheses. ${ }^{*}, * *$ and ${ }^{* * *}$ denote statistical significance at the $0.10,0.05$ and 0.01 levels, respectively. 
Figure 2: Empirical Density and Predicted Class Specific Densities
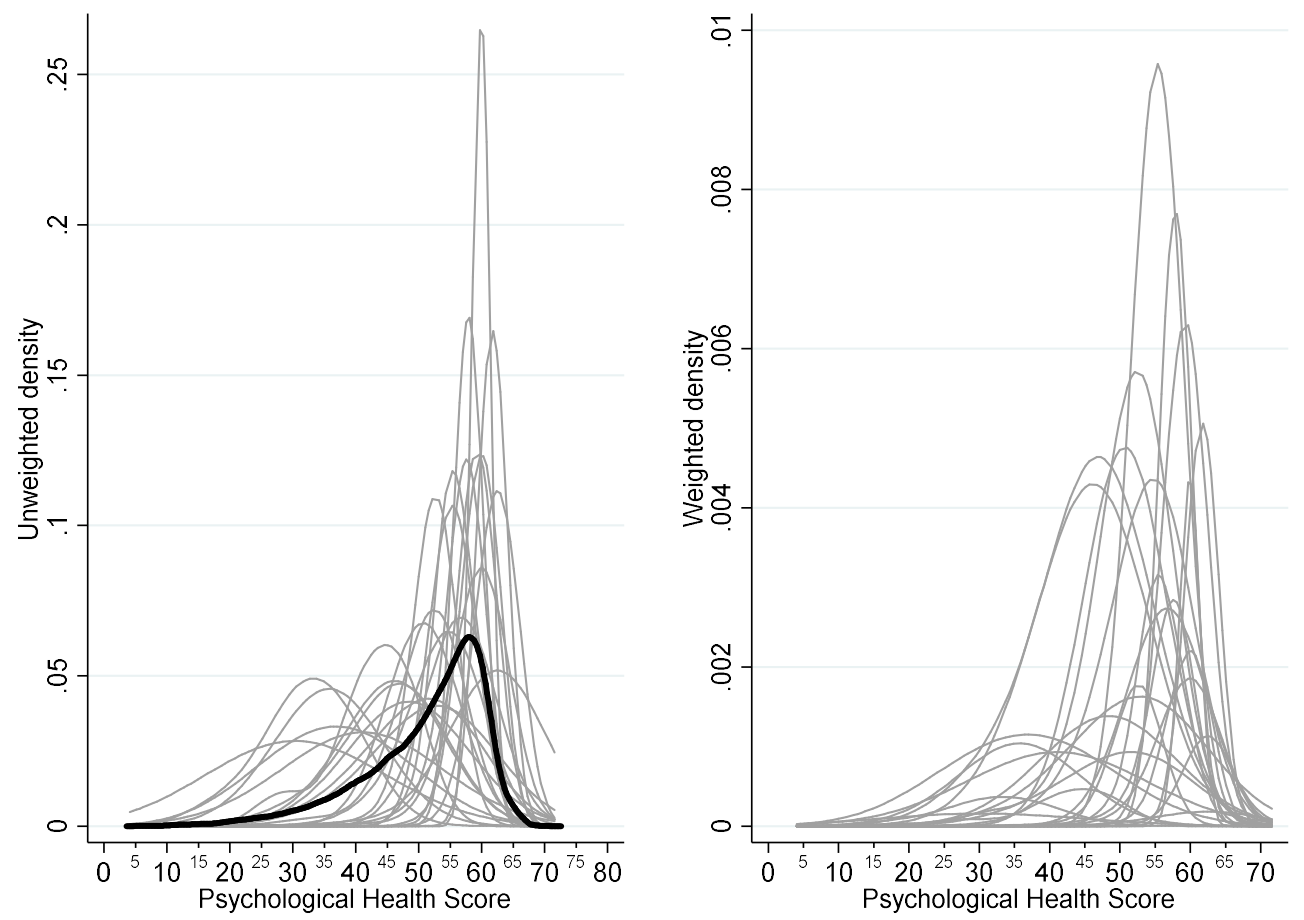

Notes: Black thick line: empirical distribution of psychological health (non-parametric fit); grey lines: unconditional class-specific distributions of psychological health simulated with the finite mixture dynamic model, weighted by the probabilities $\pi_{\mathrm{kc}}$ in the right panel, and unweighted in the left panel. 
Figure 3: Heterogeneity in the Psychological Response Profiles to a Standardised Event (SE)

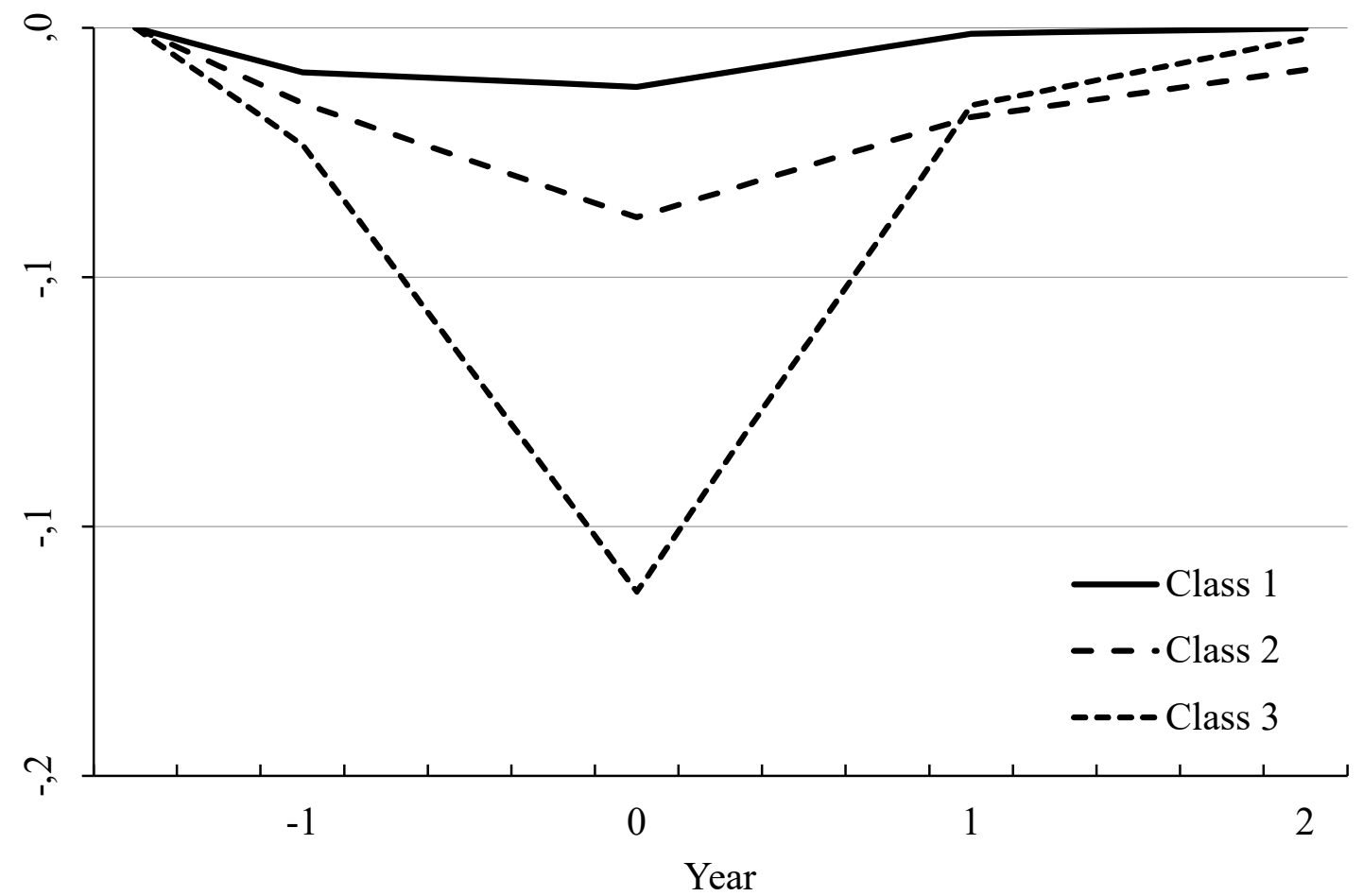

Notes: Y-axis represents the variation in psychological health in standard deviation units. $\mathrm{X}$-axis represents time in years. 
Figure 4: Heterogeneity in the Total Pyschological Loss (TPL) to a Standardised Event (SE)

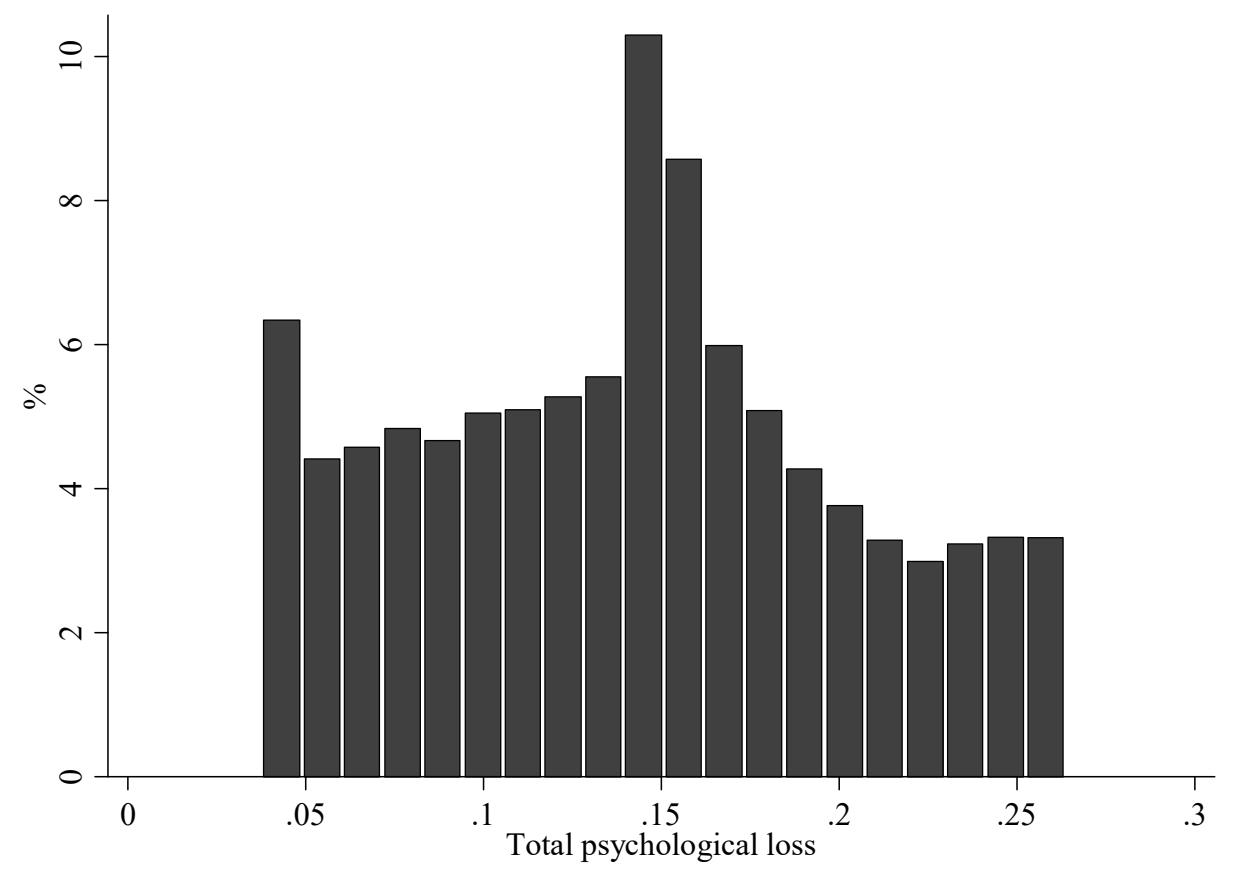

Notes: Histogram of the distribution of Total Psychological Loss (TPL) from a Standardised Event (SE). The TPL is bounded above and below by values corresponding to the most and the less resilient class. 
Table 4: Descriptive Statistics of Selected Adulthood Characteristics by Terciles of Total Psychological Loss (TPL) to a Standardised Event (SE)

\begin{tabular}{lccc}
\hline & \multicolumn{3}{c}{ Terciles } \\
\hline & 1st & 2nd & 3rd \\
\hline Clinical psychological health & & & \\
Current diagnosed depression / anxiety & $2.9 \%$ & $11.0 \%$ & $18.4 \%$ \\
Take depression/anxiety prescription meds & $1.1 \%$ & $6.2 \%$ & $8.7 \%$ \\
Seen psychiatrist/psychologist in past year & $2.1 \%$ & $5.7 \%$ & $9.5 \%$ \\
\hline
\end{tabular}

Notes: Terciles of total psychological loss from a standardised event defined using the estimated $33^{\text {rd }}$ and $66^{\text {th }}$ centiles. Sample size equals 5,721 individuals for clinical outcomes. 
Table 5: Linear Regression of Total Psychological Loss Percentile on Demographic, Cognitve Ability and Personality Traits

\begin{tabular}{|c|c|c|c|}
\hline & $\begin{array}{c}\text { Basic } \\
\underset{\text { Demographics }}{(1)}\end{array}$ & $\begin{array}{c}+ \text { Cognition } \\
\text { (2) }\end{array}$ & $\begin{array}{c}+ \\
\text { Personality } \\
\text { (3) }\end{array}$ \\
\hline Male & $\begin{array}{c}-5.006^{* * *} \\
(0.745)\end{array}$ & $\begin{array}{c}-5.385^{* * *} \\
(0.745)\end{array}$ & $\begin{array}{c}-6.300^{* * *} \\
(0.751)\end{array}$ \\
\hline Age & $\begin{array}{c}0.172 \\
(0.238)\end{array}$ & $\begin{array}{c}0.247 \\
(0.237)\end{array}$ & $\begin{array}{l}-0.146 \\
(0.227)\end{array}$ \\
\hline Age squared & $\begin{array}{l}-0.366 \\
(0.261)\end{array}$ & $\begin{array}{l}-0.486^{*} \\
(0.261)\end{array}$ & $\begin{array}{c}0.011 \\
(0.250)\end{array}$ \\
\hline Education: University degree & $\begin{array}{c}-2.685^{* * *} \\
(0.971)\end{array}$ & $\begin{array}{l}-0.165 \\
(1.039)\end{array}$ & $\begin{array}{c}0.487 \\
(1.032)\end{array}$ \\
\hline $\begin{array}{l}\text { Education: Other post-school } \\
\text { qualification }\end{array}$ & $\begin{array}{l}-1.441 \\
(0.952)\end{array}$ & $\begin{array}{l}-0.675 \\
(0.955)\end{array}$ & $\begin{array}{c}0.034 \\
(0.926)\end{array}$ \\
\hline Education: High school graduate & $\begin{array}{l}-1.188 \\
(1.293) \\
\end{array}$ & $\begin{array}{c}0.232 \\
(1.303) \\
\end{array}$ & $\begin{array}{c}-0.548 \\
(1.241) \\
\end{array}$ \\
\hline Cognitive test score & & $\begin{array}{c}-2.951^{* * *} \\
(0.428)\end{array}$ & $\begin{array}{c}-1.938^{* * *} \\
(0.418)\end{array}$ \\
\hline External locus of control index & & & $\begin{array}{l}5.912^{* * *} \\
(0.389)\end{array}$ \\
\hline Big 5 Personality: Extraversion & & & $\begin{array}{c}-1.512^{* * *} \\
(0.363)\end{array}$ \\
\hline Big 5 Personality: Agreeableness & & & $\begin{array}{c}0.274 \\
(0.411)\end{array}$ \\
\hline Big 5 Personality: Conscientiousness & & & $\begin{array}{c}-0.888^{* *} \\
(0.386)\end{array}$ \\
\hline Big 5 Personality: Emotional stability & & & $\begin{array}{c}-3.762^{* * * *} \\
(0.402)\end{array}$ \\
\hline Big 5 Personality: Openness & & & $\begin{array}{c}1.334^{* * *} \\
(0.411)\end{array}$ \\
\hline R-squared & 0.013 & 0.021 & 0.104 \\
\hline Sample Size & 6294 & 6294 & 6294 \\
\hline
\end{tabular}

Notes: Figures are coefficient estimates from three OLS regressions. The dependent variable represents an individual's estimated percentile in the total psychological loss (TPL) distribution, and ranges from 1 (lowest percentile of TPL) to 100 (highest percentile of TPL). The personality variables, and cognitive test score are all standardised to have standard deviation equal to one. Omitted education category is high school drop out. Robust standard errors are shown in parentheses. *, ** and *** denote statistical significance at the $0.10,0.05$ and 0.01 levels, respectively. 
Table 6: Linear Regression of Total Psychological Loss Percentile on Childhood Circumstances

\begin{tabular}{|c|c|c|c|}
\hline & All & Male & Female \\
\hline Male & $\begin{array}{c}-4.956^{* * *} \\
(0.752)\end{array}$ & - & - \\
\hline Age in years / 10 & $\begin{array}{c}-0.164^{* * *} \\
(0.034)\end{array}$ & $\begin{array}{c}-0.107^{* *} \\
(0.051)\end{array}$ & $\begin{array}{c}-0.200^{* * *} \\
(0.046)\end{array}$ \\
\hline Number of siblings & $\begin{array}{c}0.146 \\
(0.176)\end{array}$ & $\begin{array}{c}0.307 \\
(0.265)\end{array}$ & $\begin{array}{c}0.006 \\
(0.237)\end{array}$ \\
\hline Immigrate $\leq$ age 14 & $\begin{array}{c}0.385 \\
(1.406)\end{array}$ & $\begin{array}{c}0.587 \\
(2.122)\end{array}$ & $\begin{array}{c}0.205 \\
(1.873)\end{array}$ \\
\hline Parents divorced: mother absent & $\begin{array}{l}-1.898 \\
(3.907)\end{array}$ & $\begin{array}{l}-2.131 \\
(5.575)\end{array}$ & $\begin{array}{l}-1.838 \\
(5.433)\end{array}$ \\
\hline Parents divorced: father absent & $\begin{array}{c}0.499 \\
(2.957)\end{array}$ & $\begin{array}{l}-2.968 \\
(4.529)\end{array}$ & $\begin{array}{c}3.316 \\
(3.820)\end{array}$ \\
\hline Mother had died & $\begin{array}{l}-2.440 \\
(4.249)\end{array}$ & $\begin{array}{l}-0.936 \\
(6.327)\end{array}$ & $\begin{array}{l}-3.326 \\
(5.643)\end{array}$ \\
\hline Father had died & $\begin{array}{l}-0.705 \\
(3.280)\end{array}$ & $\begin{array}{l}-0.606 \\
(4.827)\end{array}$ & $\begin{array}{l}-0.986 \\
(4.313)\end{array}$ \\
\hline Lived without both parents & $\begin{array}{l}-1.468 \\
(2.589)\end{array}$ & $\begin{array}{l}-2.765 \\
(3.847)\end{array}$ & $\begin{array}{c}-0.072 \\
(3.382)\end{array}$ \\
\hline Mother employed at age 14 & $\begin{array}{c}0.051 \\
(0.789)\end{array}$ & $\begin{array}{c}1.824 \\
(1.186)\end{array}$ & $\begin{array}{l}-1.316 \\
(1.058)\end{array}$ \\
\hline Father occupation: Professional & $\begin{array}{l}-0.757 \\
(1.261)\end{array}$ & $\begin{array}{c}2.429 \\
(1.881)\end{array}$ & $\begin{array}{c}-3.534^{* *} \\
(1.698)\end{array}$ \\
\hline Father occupation: Technician / trade & $\begin{array}{c}1.652 \\
(1.057)\end{array}$ & $\begin{array}{c}1.171 \\
(1.569)\end{array}$ & $\begin{array}{c}1.955 \\
(1.433)\end{array}$ \\
\hline Father occupation: Community / personal service & $\begin{array}{l}1.658 \\
(2.236)\end{array}$ & $\begin{array}{l}-1.539 \\
(3.579)\end{array}$ & $\begin{array}{c}3.377 \\
(2.859)\end{array}$ \\
\hline Father occupation: Clerical \& administration & $\begin{array}{l}-2.609 \\
(1.657)\end{array}$ & $\begin{array}{l}-0.182 \\
(2.488)\end{array}$ & $\begin{array}{c}-4.897^{* *} \\
(2.205)\end{array}$ \\
\hline Father occupation: Sales & $\begin{array}{l}-0.472 \\
(1.964)\end{array}$ & $\begin{array}{l}-3.376 \\
(2.804)\end{array}$ & $\begin{array}{c}1.727 \\
(2.750)\end{array}$ \\
\hline Father occupation: Machinery operator / driver & $\begin{array}{c}3.645^{* * *} \\
(1.327)\end{array}$ & $\begin{array}{c}2.862 \\
(1.982)\end{array}$ & $\begin{array}{l}4.359^{* *} \\
(1.790)\end{array}$ \\
\hline Father occupation: Labourer & $\begin{array}{l}3.083^{* *} \\
(1.325)\end{array}$ & $\begin{array}{c}2.210 \\
(1.990)\end{array}$ & $\begin{array}{l}3.739^{* *} \\
(1.774)\end{array}$ \\
\hline General health: Very good & $\begin{array}{c}3.011^{* * *} \\
(0.899)\end{array}$ & $\begin{array}{c}4.637^{* * *} \\
(1.291)\end{array}$ & $\begin{array}{c}1.442 \\
(1.254)\end{array}$ \\
\hline General health: Good & $\begin{array}{c}6.232^{* * * *} \\
(1.154)\end{array}$ & $\begin{array}{l}8.158^{* * *} \\
(1.804)\end{array}$ & $\begin{array}{c}4.724^{* * *} \\
(1.497)\end{array}$ \\
\hline General health: Fair & $\begin{array}{c}10.560^{* * * *} \\
(1.878)\end{array}$ & $\begin{array}{c}10.645^{* * *} \\
(3.231)\end{array}$ & $\begin{array}{c}10.488^{* * * *} \\
(2.264)\end{array}$ \\
\hline General health: Poor & $\begin{array}{c}15.786^{* * *} \\
(2.925)\end{array}$ & $\begin{array}{c}19.287^{* * *} \\
(5.313)\end{array}$ & $\begin{array}{c}13.600^{* * * *} \\
(3.493)\end{array}$ \\
\hline R-squared & 0.028 & 0.022 & 0.026 \\
\hline Sample Size & 5856 & 2727 & 3129 \\
\hline
\end{tabular}

Notes: Figures are coefficient estimates from OLS regressions. The dependent variable represents an individual's estimated percentile in the total psychological loss (TPL) distribution, and ranges from 1 (lowest percentile of TPL) to 100 (highest percentile of TPL). Omitted categories are lived with both parents, manager and excellent health. A dummy variable for 71 missing observations on general health is also included as a covariate in the regression model. There are 291 fewer individuals in this analysis than in Table 5 due to missing information on childhood circumstances. Robust sstandard errors are shown in parentheses. $*{ }^{* *}$ and $* * *$ denote statistical significance at the $0.10,0.05$ and 0.01 levels, respectively. 


\section{Appendices to go online}

\section{Appendix A: Additional Results}

Table A1: Measurement of the Psychological (Mental) Health Component of the SF-36

\begin{tabular}{lcc}
\hline Domain-specific scales of the SF-36 & Factor loadings & Scoring coefficients \\
\hline Physical functioning & 0.177 & -0.084 \\
Physical role functioning & 0.282 & -0.104 \\
Bodily pain & 0.327 & -0.067 \\
General health perceptions & 0.499 & 0.062 \\
Vitality & 0.710 & 0.280 \\
Social functioning & 0.662 & 0.227 \\
Emotional role functioning & 0.579 & 0.152 \\
Mental health & 0.807 & 0.435 \\
\hline
\end{tabular}

Correlation of the MHC with life satisfaction

29,303 individuals observed at inclusion

Observations

Notes: Results shown from a factor analysis of the eight domain-specific scales of the SF-36, with a two-factor solution obtained after varimax rotation (mental health and physiological health). The factor loadings are the estimated coefficients of a 'regression' of the domain-specific scale on the two factors. The scoring coefficients are the estimated coefficients of a regression of the unstandardized mental health score on the eight domain-specific scales. 
Table A2: Estimation Results - Control variables

\begin{tabular}{l|cc}
\hline & $\begin{array}{c}\text { Dynamic RE } \\
\text { model }\end{array}$ & $\begin{array}{c}\text { Finite mixture } \\
\text { dynamic Model }\end{array}$ \\
\hline Log Household Income & $0.111^{*}$ & 0.027 \\
& $(0.063)$ & $(0.054)$ \\
Age/10 & $-1.362^{* * *}$ & $0.723^{* * *}$ \\
$($ Age/10) & $(0.384)$ & $(0.252)$ \\
& $0.159^{* * *}$ & 0.002 \\
Male & $(0.026)$ & $(0.017)$ \\
& $0.332^{* *}$ & $-0.222^{* * *}$ \\
Employed: Full-time & $(0.146)$ & $(0.060)$ \\
& $0.317^{* * *}$ & $-0.440^{* * *}$ \\
Employed: Part-time & $(0.115)$ & $(0.119)$ \\
Unemployed & $0.558^{* * *}$ & -0.028 \\
& $(0.105)$ & $(0.106)$ \\
University degree & 0.265 & 0.002 \\
& $(0.212)$ & $(0.243)$ \\
Certif./Dip. Degree & 0.043 & $0.217^{* * *}$ \\
12 years of schooling & $(0.171)$ & $(0.072)$ \\
Married or cohabiting & $0.279^{*}$ & $0.191^{* * *}$ \\
Divorced or separated & $(0.146)$ & $(0.067)$ \\
& -0.082 & $0.180^{*}$ \\
Number of children & $(0.211)$ & $(0.097)$ \\
& $0.430^{* * *}$ & 0.101 \\
Other control variables & $(0.160)$ & $(0.168)$ \\
& $0.542^{* *}$ & $0.506^{* *}$ \\
Observations & $(0.220)$ & $(0.226)$ \\
& $-0.230^{* * *}$ & $-0.174 * * *$ \\
& $(0.048)$ & $(0.046)$ \\
\hline
\end{tabular}

Notes: Estimation results of the Dynamic Random Effect and the Finite mixture dynamic Models for the sociodemographic control variables. Standard errors in parentheses. ${ }^{*} p<0.10,{ }^{* *} p<0.05,{ }^{* * *} p<0.01$. Omitted categories are: female, not active, less than grade 12 schooling, and single. 
Figure A1: Heterogeneity in the Psychological Response Profiles by Major Life Event
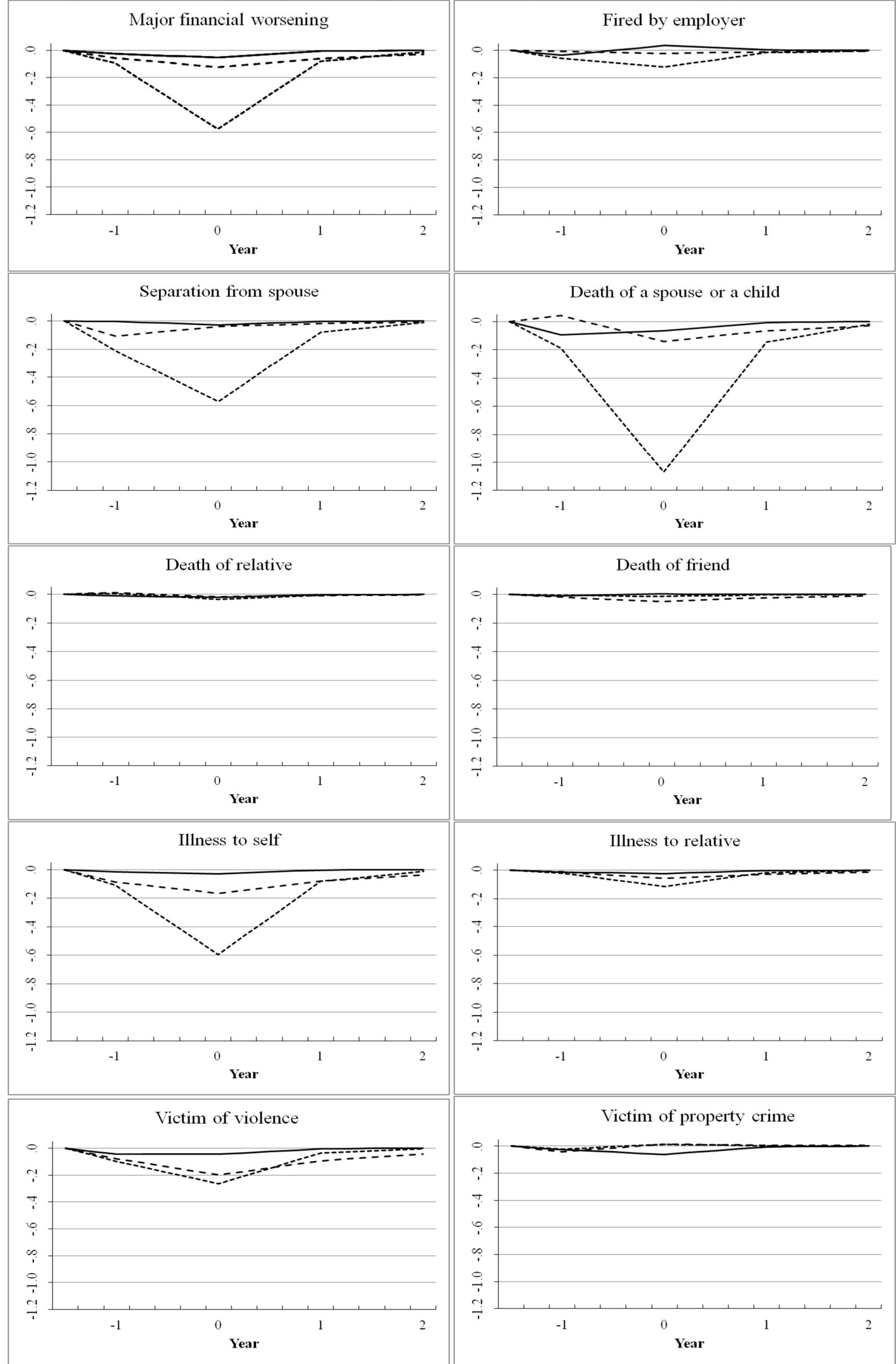

Notes: Y-axis represents variation in mental health in standard deviation units. The solid, dash and dot profiles are generated by the parameter estimates shown in columns (2), (3) and (4) in Table 2, respectively. 
Figure A2: Heterogeneity in the Total Pyschological Loss by Major Life Event
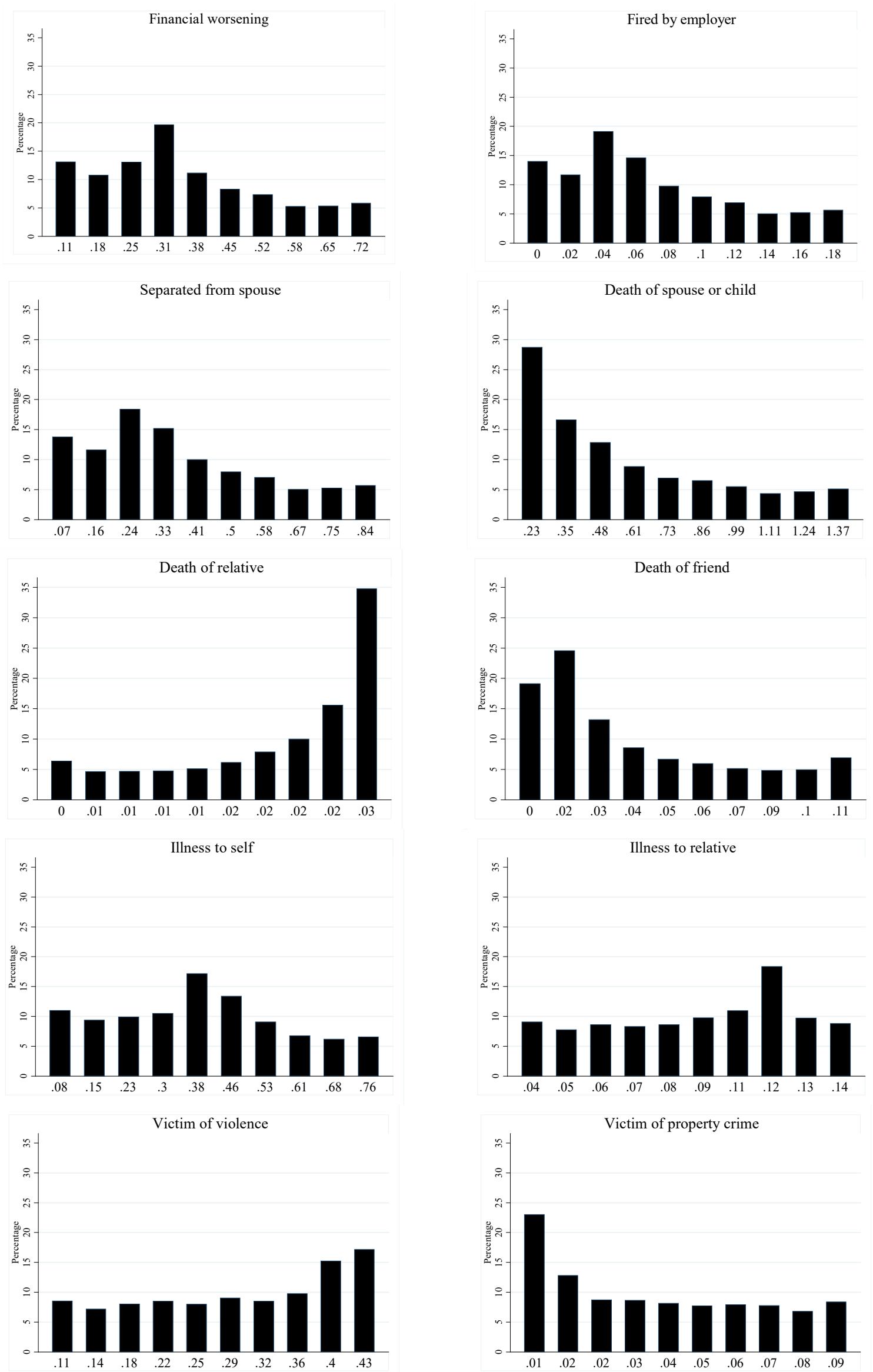

Notes: Y-axis represents percentage in sample. X-axis provides bin midpoints, which represent total standardised psychological loss (TPL). 


\section{Appendix B: Technical Appendix}

\section{Estimation procedure}

For given values of $\mathrm{C}, \mathrm{K}_{\mathrm{c}}$ and $\mathrm{L}_{\mathrm{c}}$, the individual likelihood is a discrete mixture:

$$
\begin{gathered}
\operatorname{Pr}\left(H_{i 1}, \ldots H_{i T} \mid S_{i}, x_{i}, H_{i 0}, w_{i}, \beta, \lambda\right) \propto \\
\sum_{c=1}^{C} \sum_{k=1}^{K_{c}} \sum_{l=1}^{L_{c}} \underbrace{p_{c} \pi_{k l c}}_{p_{k l c}}\left[\prod_{t=1}^{T} \phi\left(\frac{H_{i t}-\rho_{l c} H_{i t-1}-\beta^{\prime} x_{i t}-\mu_{0 c}^{\prime} S_{i t}-\mu_{1 c}^{\prime} S_{i t+1}-\lambda^{\prime} w_{i}-\alpha_{k c}}{\exp \left(\sigma_{k c}^{\prime}\right)}\right)\right]
\end{gathered}
$$

Maximising directly the corresponding log-likelihood will present computational difficulties due to the non-linearity of the model and the number of parameters. We overcome this issue by implementing the iterative Expected-Maximisation (EM) algorithm originally proposed by Dempster and Laird (1977).

E-step: For initial values of the parameters $p_{k l c}, \rho_{l c}, \beta, \mu_{0 c}, \mu_{1 c}, \lambda, \alpha_{k c}, \sigma_{k c}$ and for each individual, use the parametric specification (B1) to compute the posterior probabilities

$$
\begin{aligned}
p_{i k l c} & =\operatorname{Pr}\left(\rho_{i}=\rho_{l c}, \mu_{i}=\mu_{c}, \theta=\theta_{k c} \mid H_{i 1}, \ldots H_{i T}, S_{i}, x_{i}, H_{i 0}, w_{i}, \beta, \lambda\right) \\
& =\operatorname{Pr}\left(\rho_{i}=\rho_{l c}, \mu_{i}=\mu_{c}, \theta=\theta_{k c} \mid H_{i 1}, \ldots H_{i T}, S_{i}, x_{i}, H_{i 0}, w_{i}, \beta, \lambda\right) \\
& =\frac{p_{k l c} \operatorname{Pr}\left(H_{i 1}, \ldots H_{i T} \mid S_{i}, x_{i}, H_{i 0}, w_{i}, \rho_{i}=\rho_{l c}, \mu_{i}=\mu_{c}, \theta=\theta_{k c}, \beta, \lambda\right)}{\operatorname{Pr}\left(H_{i 1}, \ldots H_{i T} \mid S_{i}, x_{i}, H_{i 0}, w_{i}, \beta, \lambda\right)}
\end{aligned}
$$

M-step: Substitute $p_{\mathrm{klc}}$ with $p_{i k l c}$ in (B.1.) and maximize the log-likelihood to update the parameters $\rho_{l c}, \beta, \mu_{0 c}, \mu_{1 c}, \lambda, \alpha_{k c}, \sigma_{k c}$. Update $p_{\mathrm{klc}}$ by maximizing $\sum_{c=1}^{C} \sum_{k=1}^{K_{c}} \sum_{l=1}^{L_{c}} p_{i k l c} \ln \left(p_{k l c}\right)$ with respect to $p_{\mathrm{klc}}$ and subject to $\sum_{c=1}^{C} \sum_{k=1}^{K_{C}} \sum_{l=1}^{L_{c}} p_{k l c}=1$.

The $\mathrm{E}$ and $\mathrm{M}$ steps are alternated until the relative difference in two successive set of parameters (Euclidean norm) is less than a tolerance criterion. Tolerance is set to $1 \mathrm{e}-2$ for the first stage of model selection and to $1 \mathrm{e}-6$ for the second stage and final estimates. To speed up the estimation in the phase of model selection, we apply a trimming procedure in the M-step by setting $p_{i k l c}$ to 0 whenever $p_{i k l c}$ is lower than 1e-6. It is well known that the empirical identification of finite mixture models can be difficult, essentially because the likelihood function can be quite flat in some regions of the parameter space. For a better detection of the global maximum of the likelihood function, it is crucial to find good starting values for the individual weights $p_{i k l c}$ in the initial M-step. In the phase of model selection, we have experimented with ten different sets of randomly chosen starting weights for each model specification in order to be sure that we had identified global maxima. The robustness of the results were eventually checked with a simulated annealing procedure (Celeux et al., 1996). Finally, the variance of the estimator is computed by Louis' formula (Louis, 1982), with computation of likelihood scores at the level of households to account for the panel dimension of the data. 


\section{Model Selection}

There is a lack of guidance from the econometric or statistical theory on the estimation and inference on the optimal number of components in finite mixture models- here on $C, K_{c}$ and $L_{c}$. As our main objective is to identify the individual heterogeneity in the relationship between life events, we have chosen to focus on the statistical fit of the model. Following the usual practice in applied literature, we here rely on a penalized-likelihood criterion - the Bayesian Information Criterion (BIC: McLachlan and Peel, 2000, chap. 6). The lower is the BIC the better is the fit. Alternative information criterion, such as the Akaike Information Criterion or the Consistent Akaike Information Criterion, do not change the choice of the final specification. Note also that it is difficult to use standard likelihood ratio statistics because it has a non-standard limiting distribution when one compares models with different numbers of components (Liu and Shao, 2003). Recent developments in this area (e.g. Chen et al., 2012) are, to the best of our knowledge, not applicable to our model.

There are a large number of candidate specifications. We have chosen to restrict our attention to specifications with $C=2, C=3$ or $C=4$, and the same number of components $L_{c}$ and $K_{c}$ for all $c$. We also have estimated specifications with two slope classes $(C=2)$ and a maximum of two components for the autoregressive parameter $\rho\left(L_{c}=1\right.$ or $\left.L_{c}=2\right)$. These specifications did never produce better results than specifications with $C=4$ and only one autoregressive parameter per slope class. This is not surprising as the former can be derived by imposing restrictions on the latter. We have also been unable to estimate consistently models with $K_{c}$ greater than 12 for $C$ greater than 2. When the number of components $\sum_{c} K_{c} L_{c}$ becomes large, then the mass of one or several components tend to zero. Therefore, Table B1 below reports $B I C$ values only for the specifications for which estimation was easily reproducible: convergence to the same global maximum for a number of different starting values.

In a pre-selection step, we set tolerance at $1 \mathrm{e}-2$ and the trimming parameter at $1 \mathrm{e}-6$. Increasing the number of points for the distribution of the intercept and the variance $\left(\mathrm{K}_{\mathrm{c}}\right)$ increases the fit (lower BIC). Table B1 shows that the model with $\mathrm{C}=3$ components for modelling the heterogeneity in the short-term impact of life events $(\mu), L_{c}=1$ and $K_{c}=10$ for all $c$, seems to provide the best fit (upper panel). However, decreasing $K_{c}$ to 9 , does not result in a large loss of quality. Hence, in a second step (bottom line), we have tightened up the convergence criterion (to 1e-6) and relaxed the trimming parameter (to 1e-32). Note that the BIC decreases again and, now, the specification with $C=3, L_{c}=1$ and $K_{c}=9$ provides the best fit. 
Table B1: BIC

\begin{tabular}{cccccccc}
\hline $\mathrm{C}$ & $\left\{\mathrm{L}_{\mathrm{c}}\right\} \downarrow$ & $\mathrm{K}_{\mathrm{c}}$ & 7 & 8 & 9 & 10 & 11 \\
$\downarrow$ & \multicolumn{7}{c}{$\rightarrow$} \\
\hline \multicolumn{7}{c}{ Step 1: convergence tolerance $=1^{e-2}$; trimming $=1^{e-6}$} \\
2 & $\{1,1\}$ & 430666 & 430590 & 430601 & 430557 & 430556 \\
2 & $\{1,2\}$ & 430472 & 430453 & 430460 & 430410 & 430471 \\
2 & $\{2,2\}$ & & 430488 & 430389 & 430453 & 430437 & 430456 \\
3 & $\{1,1,1\}$ & 430341 & 430265 & $\mathbf{4 3 0 1 6 9}$ & $\mathbf{4 3 0 1 6 2}$ & $\mathbf{4 3 0 3 0 3}$ \\
4 & $\{1,1,1,1$ & & $\mathbf{4 3 0 2 9 5}$ & $\mathbf{4 3 0 2 4 2}$ & 430169 & 430316 & 430383 \\
\hline \multicolumn{7}{c}{ Step 2: convergence tolerance $=1^{e-6} ;$ trimming $=1^{e-64}$} \\
3 & $\{1,1,1\}$ & BIC & 429581 & 429409 & $\mathbf{4 2 9 2 9 6}$ & 429420 \\
\hline \hline
\end{tabular}

Figure 2 illustrates the fit of the model. The left panel 2a presents in grey the estimated density functions of psychological health for each of the 27 components. The black line represents the empirical density of psychological health for the estimation sample. The right panel $2 \mathrm{~b}$ presents the same estimated density functions, scaled by their weights in the population. They add up to adjust to the empirical density of psychological health in black. 


\section{Appendix C: Derivation of Cognitive Ability and Personality Traits}

Cognitive ability is measured in Waves 12 and 16 of HILDA using three tests: (1) Backwards Digits Span (BDS) test; (2) a 25-item version of the National American Reading Test (NART); and (3) the Symbol-Digit Modalities (SDM) test. The BDS is a traditional sub-component of intelligence tests and measures working memory span. The interviewer reads out a string of digits, which the respondent has to repeat in reverse order. NART measures pre-morbid intelligence. Respondents have to read aloud and pronounce correctly 25 irregularly spelled words. SDM is a test where respondents have to match symbols to numbers according to a printed key that is given to them. It was originally developed to detect cerebral dysfunction but is now a recognised test for divided attention, visual scanning and motor speed. To derive a summary measure for cognitive ability, we applied a factor analysis to all three test scores, and the first factor is then predicted and standardised to have a mean of zero and a standard deviation of one.

Personality is measured in HILDA in Waves 5, 9, 13 and 17 using a version of the Big-5 Personality Inventory in which 5 personality traits are quantified: extraversion, agreeableness, conscientiousness, openness to experience, and emotional stability (sometimes reversed and labelled neuroticism). Each of these trait variables have been re-scaled to have a mean of zero and a standard deviation of one, with higher scores indicating that the individual is well described by the personality type. Each individuals in our estimation sample is assigned personality values from the earliest possible wave.

Our second measure of personality (or non-cognitive ability) is locus of control, which is described by Rotter (1966) as a "generalized attitude, belief, or expectancy regarding the nature of the causal relationship between one's own behavior and its consequences". It is generated from a locus of control questionnaire included in Waves 3, 4, 7, 11 and 15 that requires respondents to evaluate seven statements (e.g. "I have little control over the things that happen to me") using a one (strongly disagree) to seven (strongly agree) scale. We add the responses (some items reversed) to form a locus of control index, which is again re-scaled to have mean zero and standard deviation one. Higher scores indicate that the individual has external control tendencies, implying that they believe their outcomes are due to external forces rather than due to their own efforts. As with the Big-5 personality variables, we assign each individual locus of control information from the earliest possible wave. 